\title{
Diurnal precipitation and high cloud frequency variability over the Gulf Stream and over the Kuroshio
}

\author{
Shoshiro Minobe $\cdot$ Shogo Takebayashi
}

Received: 10 December 2013 / Accepted: 2 July 2014 / Published online: 16 July 2014

(C) The Author(s) 2014. This article is published with open access at Springerlink.com

\begin{abstract}
Recent studies show mid-latitude western boundary currents (WBCs) substantially influence the atmosphere aloft, and an important feature is enhanced rain band over the WBCs in climatological mean field. However, how such long-term, climate phenomena are related to shorter, weather timescale phenomena are generally remained to be explored. In this paper, diurnal precipitation and cloud variations are investigated global mid-latitude oceans with emphasis on air-sea interactions over WBCs using satellite-derived precipitation and outgoing longwave radiation (OLR) datasets. Strong 24-h period components of precipitations are found over the Gulf Stream in summer and over the Kuroshio in the East China Sea in early summer (Baiu-Meiyu season), respectively. Similar diurnal precipitations are not observed in WBCs in the Southern Hemisphere year around. The diurnal precipitation cycles over the Gulf Stream and the Kuroshio exhibit peak phases in the early to late morning for the Gulf Stream and late morning to early afternoon for the Kuroshio, with southeastward phase propagations. High cloud frequency derived from OLR data exhibit consistent diurnal cycles. A substantial difference of diurnal cycles between the Gulf Stream and the Kuroshio regions are associated with the large-scale Baiu-Meiyu rain and cloud bands for the latter region. Diurnal precipitation and high cloud variability is found in the vicinity of the Kuroshio itself, embedded in the Baiu-Meiyu rain and cloud bands distributing in a wider area without a strong diurnal component. The spatial
\end{abstract}

S. Minobe $(\bowtie) \cdot S$. Takebayashi

Department of Natural History Sciences,

Graduate School of Science, Hokkaido University,

Room 319, Rigaku Building No 8, N10, W8, Kita-ku,

060-0810 Sapporo, Japan

e-mail: minobe@sci.hokudai.ac.jp and seasonal distributions of the diurnal variability over these WBCs strongly suggests that the diurnal precipitation and cloud cycles are essential aspects of deep heating mode of atmospheric response recently reported for these WBCs. These results indicate that these WBCs in the Northern Hemisphere play an important role in modulating shortterm precipitation variations, and on the other hand diurnal variability can be a substantial agent for the mid-latitude air-sea interaction.

Keywords Climate process - Air-sea interaction .

Western boundary currents $\cdot$ Mid-latitude .

Scale-interaction $\cdot$ Observational data analysis

\section{Introduction}

How mid-latitude oceans fronts, associated with western boundary currents (WBCs) and meso-scale eddies, influence the overlying atmosphere is a rapidly developing research field. In particular, air-sea interactions over four mid-latitude WBCs, i.e., the Gulf Stream, the Kuroshio and its extension, the Agulhas Return Current, and the Brazil-Malvinas currents, have attracted much attention (see reviews by Chelton et al. 2004; Xie 2004; Small et al. 2008; Chelton and Xie 2010). Among these four regions, prominent tropospheric responses to the WBCs above the Marine Atmospheric Boundary Layer (MABL) were reported for the Gulf Stream (Minobe et al. 2008, 2010; Czaja and Blunt 2011), the Kuroshio Extension (Tokinaga et al. 2009; Czaja and Blunt 2011) and the Kuroshio in the East China Sea (Xu et al. 2011; Sasaki et al. 2012), characterized by enhanced rain accompanied by ascent. Also, cloud distribution and tropospheric temperatures are modified over the Agulhas Return Current region (Liu et al. 
2007; Shimada and Minobe 2011). These studies, however, mainly investigated seasonal or annual mean climatologies. The atmospheric responses found in the time mean fields must involve time varying phenomena on shorter timescales. This is especially true for precipitation, because its occurrence is highly intermittent and is closely related to shorter timescale phenomena such as synoptic scale disturbances and diurnal variability.

Most of the previous studies that have investigated the relation between shorter timescale phenomena and airsea interaction over the mid-latitude WBCs have focused on synoptic scale variations. Synoptic scale disturbances strongly modify air-sea heat fluxes in WBC regions as found in observations (e.g., Alexander and Scott 1997; Zolina and Gulev 2003; Shaman et al. 2010; Rudeva and Gulev 2011) and also in modeling studies (e.g., Nonaka et al. 2009; Taguchi et al. 2009; Brayshaw et al. 2011). The sensible and latent heat fluxes are important in maintaining the surface baroclinicity (e.g., Hoskins and Valdes 1990; Nakamura et al. 2004, 2008), which is crucial for developments of extratropical cycles (Hoskins et al. 1985) and thus important in determining the nature of the storm tracks (e.g., Inatsu et al. 2003; Inatsu and Hoskins 2004; Brayshaw et al. 2008, 2011; Ogawa et al. 2012). In particular, surface storm tracks and high wind distributions are strongly affected by WBCs (Sampe and Xie 2007; Joyce et al. 2009; Booth et al. 2010), and atmospheric latent heating associated with precipitation plays an important role in cyclone development over WBC regions (e.g., Kuo et al. 1991; Kuwano-Yoshida et al. 2010; Booth et al. 2012). Furthermore, an observational study by Nakamura et al. (2012) showed that wintertime extratropical cyclone tracks are modified by the Kuroshio's large meander south of Japan, which was confirmed in the numerical experiment by Hayasaki et al. (2013).

In contrast to the large body of work on synoptic scale variability, the linkage between air-sea interaction over the WBCs and diurnal variability is much less well studied. Most studies of diurnal precipitation cycles focused their attention on diurnal variations over land (e.g., Wallace 1975; Oki and Musiake 1994) or in the tropics (e.g., Janowiak et al. 1994; Yang and Slingo 2001; Nesbitt and Zipser 2003; Kikuchi and Wang 2008), probably reflecting data availability in early studies and also the overall tendency for strong diurnal variations over land and/or the tropics. However, one can see that a relatively strong diurnal cycle of precipitation occurs over the Gulf Stream in a global analysis (Fig. 2 in Kikuchi and Wang 2008) or in a regional analysis focused on North America (Fig. 6 in Dirmeyer et al. 2012) in summer, though the possible dependency of this diurnal precipitation to the Gulf Stream was not mentioned in these papers. Diurnal cloud variations over the Gulf Stream region were also reported a decade ago by
Alliss and Raman (1995), though their analysis was limited to the western portion of the Gulf Stream (west of $71^{\circ} \mathrm{W}$ ) using 6-hourly data, which is coarsely sampled compared with hourly or 3-hourly sampled data used in recent studies (e.g., Dai et al. 2007; Kikuchi and Wang 2008).

Given the fact that the oceanic diurnal precipitations are generally stronger in the tropics than in the mid-latitudes, it is worthwhile to note that tropical-like atmospheric responses to mid-latitude WBCs have been identified in recent studies. Minobe et al. (2010) found a stark difference in the atmospheric response over the Gulf Stream between the summer and winter seasons. In summer, maximum upward winds are found in the middle of the troposphere, just above the enhanced precipitation over the Gulf Stream, accompanied by horizontal convergence in the lower troposphere. Atmospheric heating has its maximum also in the mid-troposphere, where convective latent heating dominates. The authors referred to this type of atmospheric response as the deep heating mode. In winter, upward winds have their maximum in the lower troposphere $(850$ $700 \mathrm{hPa}$ ), and the corresponding horizontal convergence is mostly limited to the MABL, though summer time convergence is not confined in this layer. The corresponding atmospheric heating consists of sensible heating (including vertical diffusion of heat in the MABL) and convective latent heating just above the top of the MABL, resulting in total atmospheric heating that exhibits a maximum in the lower troposphere. The authors referred to this type of atmospheric response as the shallow heating mode, and showed that a bimodal variation of the atmospheric heating profile exists between deep and shallow distributions.

A deep heating mode as energetic as that over the Gulf Stream is also found in the atmospheric response over the Kuroshio in the East China Sea in June, i.e., middle of early summer rain season in this region (Sasaki et al. 2012). This long-lasting precipitation phenomenon prevailing from southeast China to Japan is called Baiu in Japan and Meiyu in China. The Baiu-Meiyu rainband is caused by basin-scale interactions between the atmosphere, land and the ocean. Moisture transport by low-level jets along the western flank of the subtropical high is a key factor in generating the Baiu-Meiyu rainband (e.g., Ninomiya and Akiyama 1992), whereas horizontal temperature advection from the Tibetan Plateau also plays an important role in determining its location (Sampe and Xie 2010). Sasaki et al. (2012) foundthat a localized atmospheric response to the Kuroshio, with the deep heating mode, is embedded in the large-scale Baiu-Meiyu rainband. A weak deep heating mode is also observed over the Kuroshio Extension in summer (Minobe et al. 2010; Tokinaga et al. 2009), and over the East China Sea in spring (Xu et al. 2011). The presence of tropical-like atmospheric responses to the Gulf Stream may be related to the aforementioned diurnal precipitation 
over the Gulf Stream. If so, is similar diurnal precipitation variability also found over the Kuroshio in the East China Sea? Can prominent diurnal precipitations be found in WBCs in the Southern Hemisphere? Minobe et al. (2010) suggested that for an energetic deep heating mode to exist, sea-surface temperature (SST) warmer than $24-26{ }^{\circ} \mathrm{C}$ may be necessary, and furthersuggested that the absence of the deep heating mode (i.e. as strong as over the Gulf Stream) for the WBCs in the Southern Hemisphere due to the relatively cold SSTs in those regions.

The purpose of the present paper is, therefore, to investigate diurnal variability of precipitations over mid-latitude WBCs. For this purpose, we analyze a satellite-derived precipitation dataset globally in order to investigate the overall connection of diurnal variations to the WBCs and also regionally to determine the detailed spatio-temporal structures. The rest of the present paper is organized as follows. In Sect. 2, we describe the datasets and analysis method. In Sect. 3, diurnal precipitations are analyzed globally. This global analysis indeed reveals strong diurnal precipitation variability in summer over the Gulf Stream and over the Kuroshio in the East China Sea. Thus, in the following two sections (Sects. 4, 5), we conduct closer analyses for these two regions. Discussion and conclusions are presented in Sect. 6.

\section{Data and method}

We analyzed a satellite-derived precipitation dataset and an outgoing longwave radiation (OLR) dataset. The precipitation dataset is GSMaP MVK version 5 (Ushio et al. 2009). The rain rates in this dataset are estimated using a Kalman filter from multiple micro-wave satellites combined with an infra-red (IR) dataset provided by National Oceanic and Atmospheric Administration-Climate Prediction Center (NOAA-CPC), and are provided on an hourly, $0.1^{\circ} \times 0.1^{\circ}$ grid from March 2000 to December 2010. The IR data are used for moving vectors of estimated precipitation and also for the estimation of the precipitation itself from brightness temperatures. It should be noted that most of the previous studies of diurnal precipitation used the TRMM 3B42 dataset, which is on a three-hourly $0.25^{\circ} \times 0.25^{\circ}$ grid (Huffman et al. 2007), whereas the GSMaP MVK has higher spatial and temporal resolutions than that.

We also analyzed a global 3-hourly, $1^{\circ} \times 1^{\circ}$ OLR dataset of NASA/GEWEX Surface Radiation Budget (SRB) project (Stackhouse et al. 2004). This dataset is available from NASA Langley Research Center's Atmospheric Science Data Center for a period from July 1982 to December 2007, and analyzed in this study from 2000 to 2007 . The data was briefly analyzed by Minobe et al. (2008), who reported frequent daytime high cloud occurrence along the Gulf Stream based on occurrence frequency of OLR levels lower than $160 \mathrm{~W} / \mathrm{m}^{2}$, which roughly corresponds to a cloud-top height of about $300 \mathrm{hPa}$. Following their approach, we also examine occurrence rate of OLR smaller than $160 \mathrm{~W} / \mathrm{m}^{2}$ as a measure of high cloud frequency. In order to know whether the major features found in the OLR-based high cloud frequency are consistent with independent cloud data, we also examine cloud amount for high-level clouds of D2 dataset of International Satellite Cloud Climatology Project (ISCCP) for a period from 2000 to 2009 (Rossow and Schiffer 1999). Spatial resolution D2 dataset is $2.5^{\circ} \times 2.5^{\circ}$, coarser than that of OLR, with the 3-hourly sampling interval. High-level clouds in ISCCP D2 dataset are defined clouds that have cloud top pressures are smaller than $440 \mathrm{hPa}$, and thus include lower clouds than those used for OLR-based high-cloud frequency.

Diurnal climatologies are calculated for each month and also for each season, and from these the diurnal amplitude and phase of the 24-h Fourier component are estimated. The phase is expressed by the local solar time (LST) for the maximum of this Fourier component, where LST is calculated from coordinated universal time (UTC) with longitudinal distance between each grid point and $0^{\circ}$. Also, we examine relative amplitude, given by the amplitude divided by the mean value. If diurnal variability consists of pure sinusoidal wave of 24-h component, relative amplitude is in a range between 0 and $100 \%$. In this case, a relative amplitude of $100 \%$ means that the daily minimum is $0 \%$ and the maximum is $200 \%$ of the mean value. A relative amplitude can be larger than $100 \%$, when precipitation occur in a narrower time range than that expected from a sinusoidal wave.

In order to show geographical relations between atmospheric and oceanic structures, we also use climatological satellite-derived SST and surface geostrophic current velocity data. SST data used for calculating climatological SSTs are optimal interpolation SST ver. 2 on a daily, $0.25^{\circ} \times 0.25^{\circ}$ grid (Reynolds et al. 2007). Weekly surface geostrophic current velocities, estimated from satellite altimeter, are provided by AVISO on a $1 / 3^{\circ} \times 1 / 3^{\circ}$ grid (http://www.aviso.oceanobs.com/en/data/ product-information/duacs/ssaltoduacs-products.html).

\section{Global view}

Before analyzing the global diurnal cycles, in order to get some idea of precipitation and evaporation distributions associated with mid-latitude WBCs, global maps of annual mean rain rate and evaporations are shown in Fig. 1. Previous studies examined these parameters associated with WBCs over the Northern Hemisphere (Minobe et al. 2008, 2010; Tokinaga et al. 2009; Sasaki et al. 2012) but 
Fig. 1 Annual mean climatology of a rain rate from GSMaP MVK from March 2000 to November 2010, b evaporation from the J-Ofuro dataset from January 2000 to December 2006, c surface geostrophic current velocities provided by AVISO from January 2000 to December 2010 (a) Rain rate, GSMaP MVK

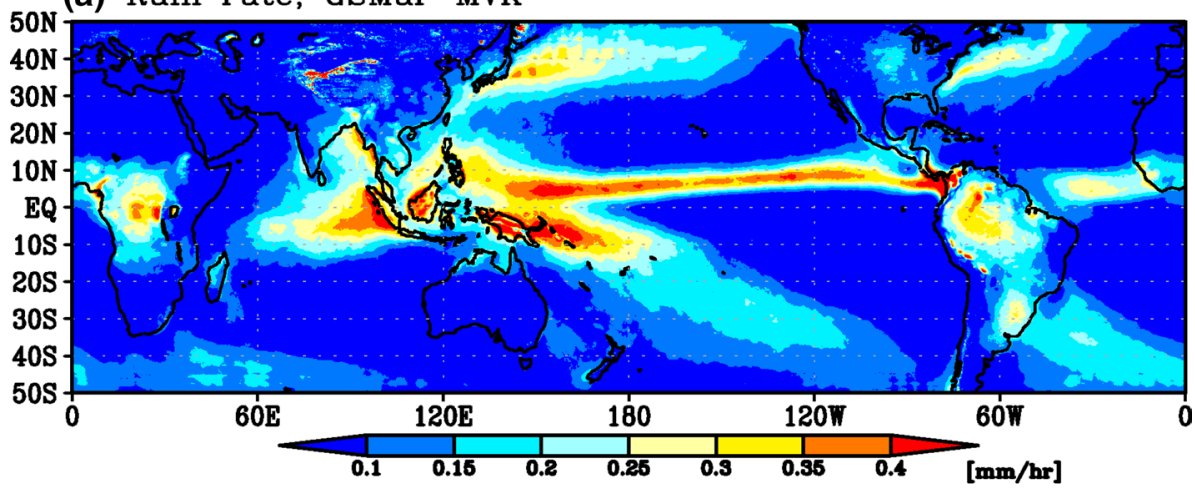

(b) Evaporation, J-Ofuro

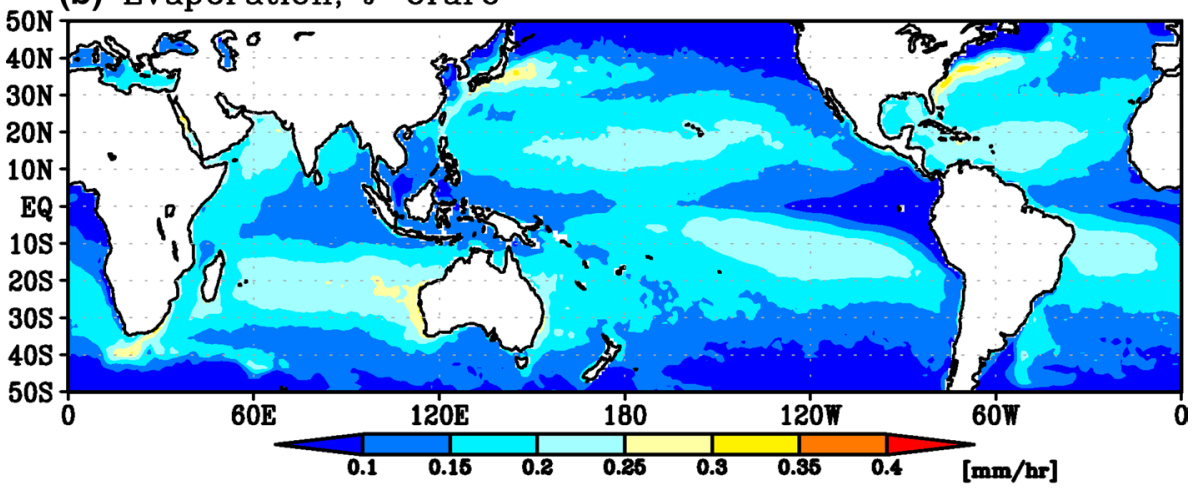

(c) Absolute Surface Geostrophic Velocity, AVISO

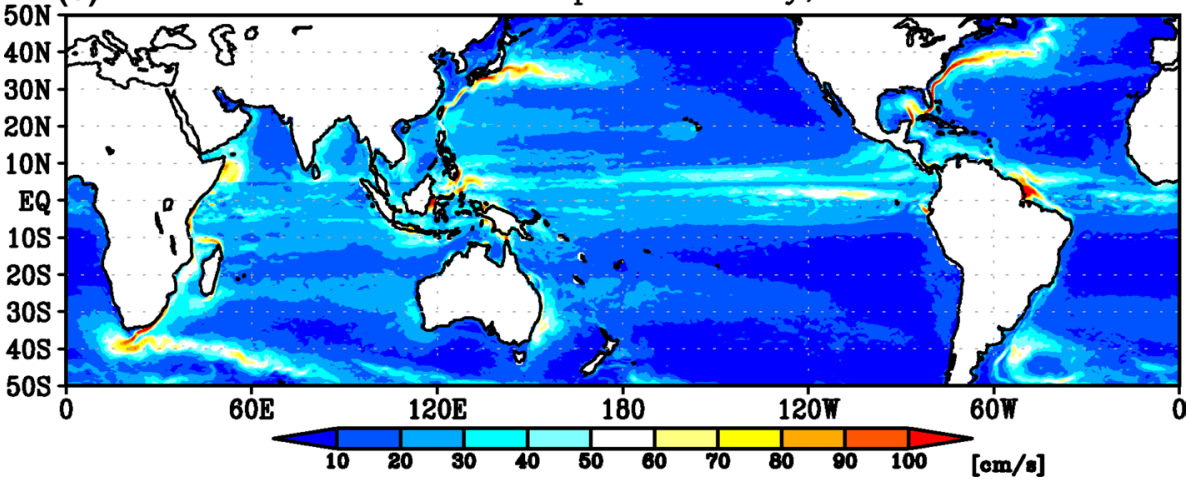

did not compare them with those in the Southern Hemisphere. Evaporation data is taken from satellite-derived data set Japanese Ocean Flux (J-Ofuro) dataset version 2.1 (Kubota and Tomita 2007) for a period from 2000 to 2006. For comparison of the precipitation and evaporation with the geographic locations of the WBCs, the absolutevalue of the surface geostrophic velocity is also shown in the figure. In addition to regions of strong rain rate over the tropics including the inter-tropical convergence zone (ITCZ) and the South Pacific convergence zone (SPCZ), enhanced rain also occurs over the Gulf Stream, the Kuroshio and the Kuroshio Extension, consistent with previous observational studies (Minobe et al. 2008, 2010; Tokinaga et al. 2009; $\mathrm{Xu}$ et al. 2011; Sasaki et al. 2012). These mid-latitude precipitation bands are accompanied by enhanced local evaporation, in contrast to the relatively weak local evaporation in the tropical convergence zones. Over the Agulhas Return Current, slightly enhanced evaporation and precipitation is found, though the structure of the latter is somewhat noisy. The enhanced precipitation and accompanying atmospheric heating can be related to therelatively deep penetration of the oceanic influence on the troposphere in this region (Liu et al. 2007; Shimada and Minobe 2011). The magnitude of precipitation over the Agulhas Return Current, however, is much smaller than that over the WBCs in the Northern Hemisphere. In the Brazil/Malvinas confluence region in the western South Atlantic, the evaporation peaks along the poleward flowing Brazil current, but no corresponding precipitation band is observed. The strong rainbands over the Northern Hemisphere WBCS, and 
Fig. 2 a Amplitude, b relative amplitude and $\mathbf{c}$ phase of diurnal precipitation cycle in boreal summer (June-August). Gray areas over the ocean in panel $\mathbf{a}$ are excluded from the analysis, because missing data rate due to presence of ice is larger than $20 \%$. The values in panels $\mathbf{b}, \mathbf{c}$ are drawn for the region where the amplitudes are larger than $0.02 \mathrm{~mm} / \mathrm{h}$. Horizontal lines indicate $25^{\circ} \mathrm{N} / \mathrm{S}$

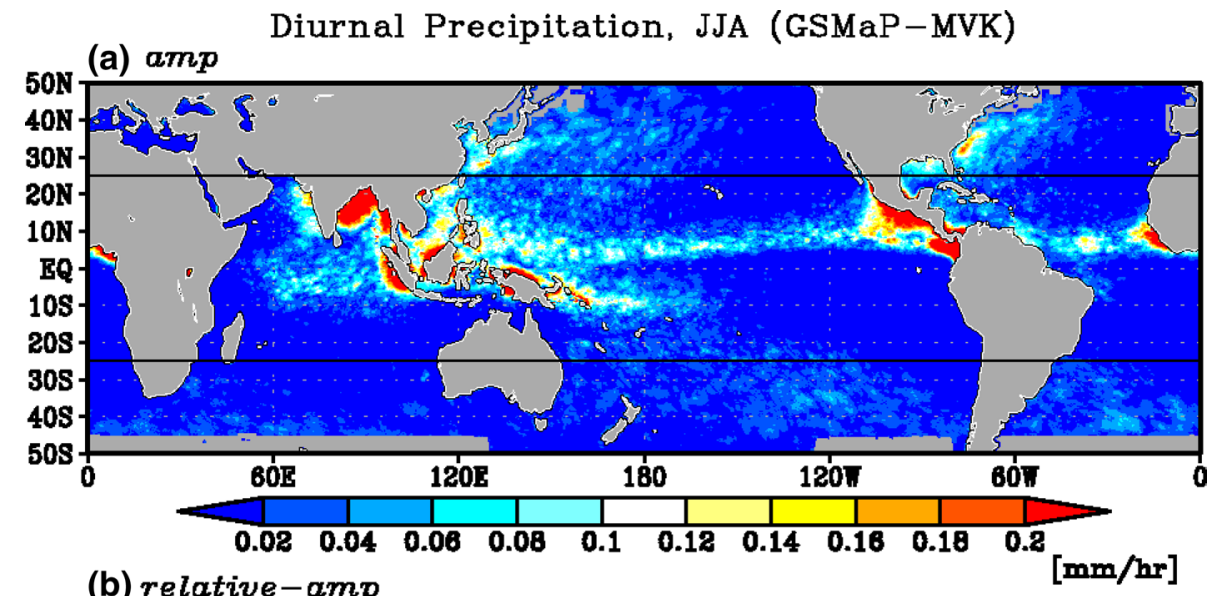

(b) relative-amp

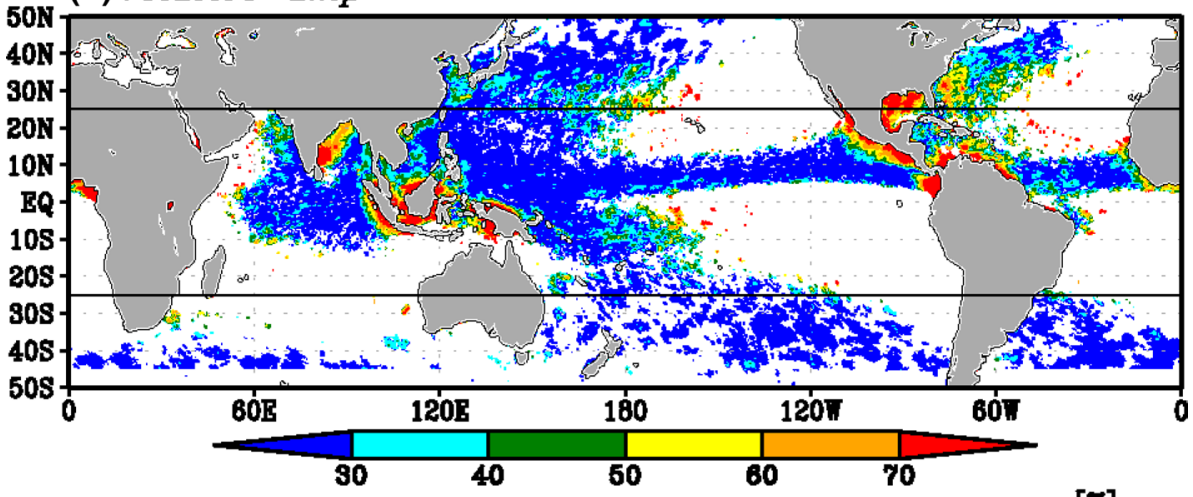

(c) phase

[x]

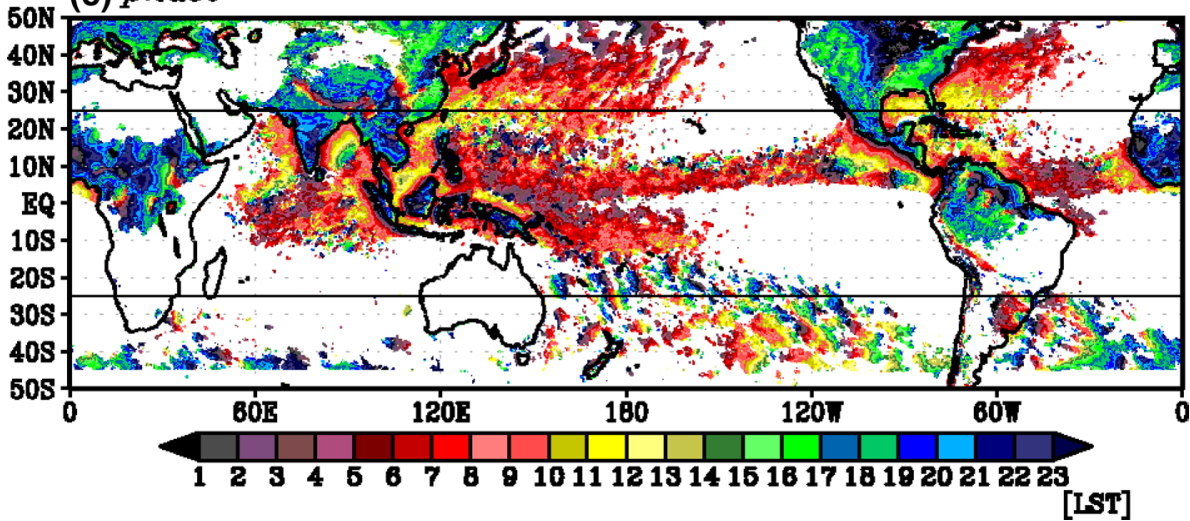

weak rainband over the Agulhas Return Current are also seen in the National Centers for Environmental Prediction (NCEP)-Climate Forecast System Reanalysis (CFSR) dataset (Saha et al. 2010).

Diurnal precipitation amplitudes derived from GSMaP MVK dataset are now examined for each season. Figure $2 \mathrm{a}$ shows that diurnal amplitudes of precipitation are strong over the Gulf Stream and the Kuroshio in the East China Sea and south of Japan over mid-latitude (poleward of $25^{\circ} \mathrm{N} / \mathrm{S}$ ) oceans in boreal summer, in addition to widely known strong diurnal precipitation in the tropics near lands and in the ITCZ and SPCZ. The maximal amplitudes reach $0.2 \mathrm{~mm} / \mathrm{h}$ over both the Gulf Stream and the Kuroshio.
The relative amplitudes (see Sect. 2) of the diurnal precipitation over the Gulf Stream are about 40-70\%, and over the Kuroshio are 30-60 \% (Fig. 2b). These values are much higher than general values, found to be $10-30 \%$ over much of the ocean (Dai et al. 2007). The relative amplitudes over the Gulf Stream and the Kuroshio indicate a possibility that the diurnal cycle of precipitation in these regions provides an important contribution to the mean rain rate.

Figure $2 \mathrm{c}$ shows phases at which the 24 -h precipitation component reaches its maximum in LST. A prominent feature is the contrasting phase over land and ocean. It is known that the diurnal cycle tends to have its maximum 
Fig. 3 Same as Fig. 2, but for the boreal winter (December-February) (a) $a m p$

Diurnal Precipitation, DJF (GSMaP-MVK)

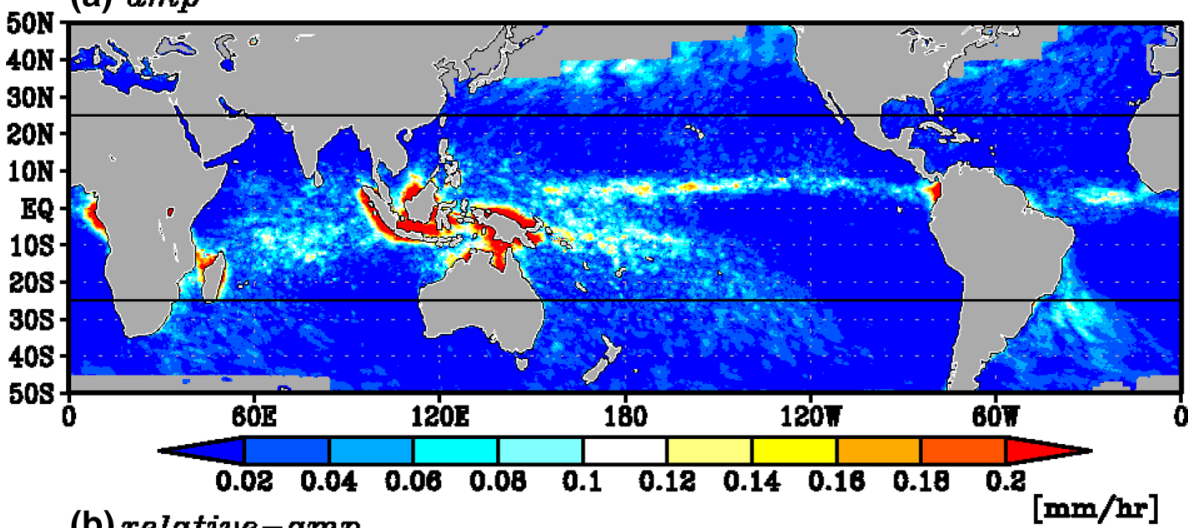

(b) relative-amp

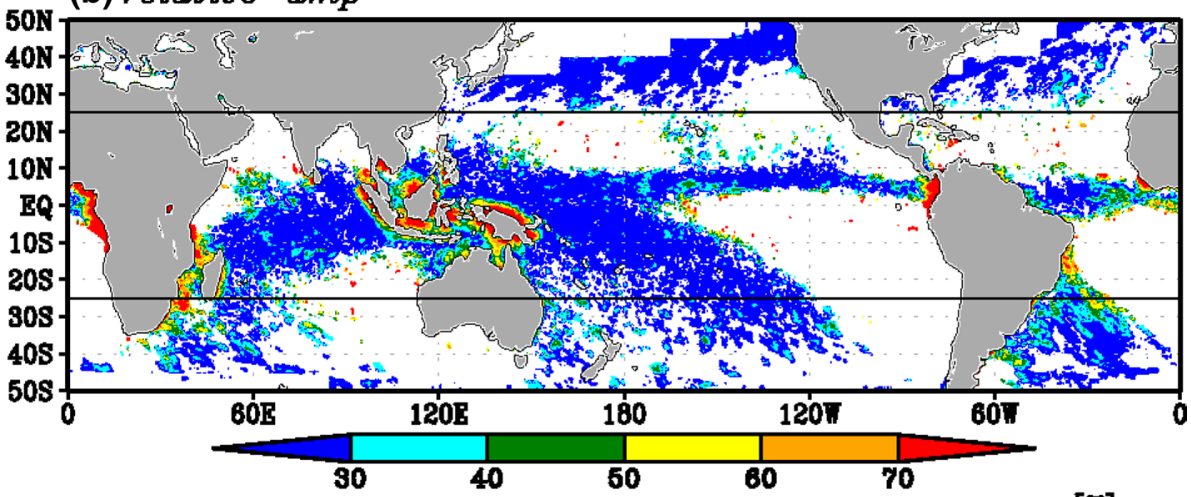

(c) phase

[x]

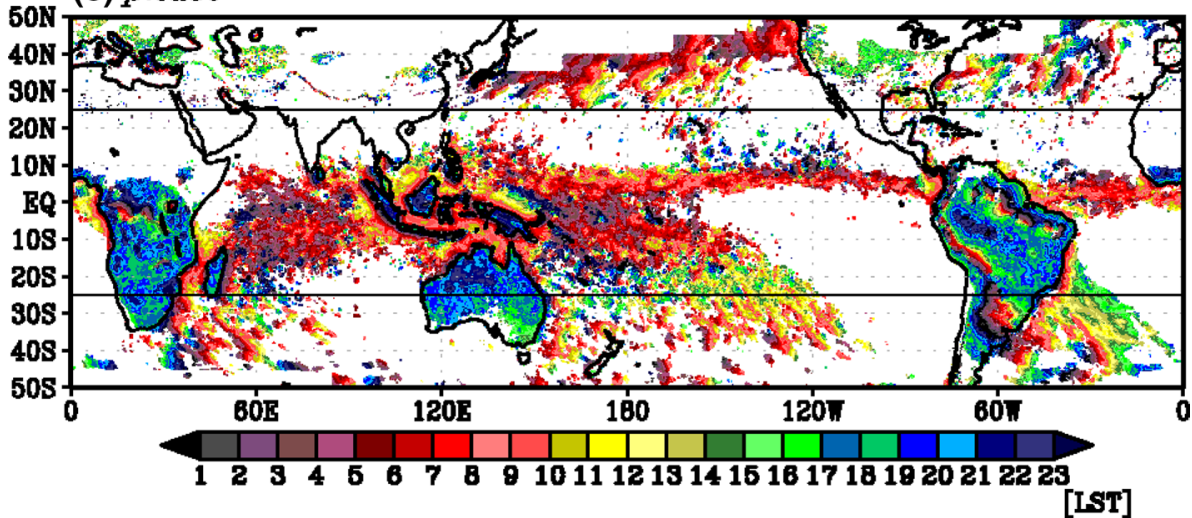

over the ocean in local morning, while over land it peaks in the local afternoon to evening (e.g., Dai et al. 2007; Kikuchi and Wang 2008). The phases over the Northern Hemisphere WBCs follow these general tendencies.

In boreal winter, diurnal precipitations in mid-latitude oceans are generally weak, especially over the mid-latitude WBCs (Fig. 3a). Moderately strong amplitudes are found over a region roughly corresponding to the North Pacific storm track (Hoskins and Hodges 2002), but corresponding relative amplitudes are generally smaller than $30 \%$ (Fig. 3b). In the Southern Hemisphere, moderately large amplitudes $\sim 0.06 \mathrm{~mm} / \mathrm{h}$ are found off Brazil in the South
Atlantic, with the phases indicating a peak around noon (Fig. 3c). Although the diurnal cycles in the North Pacific and in the South Atlantic during boreal winter could be an interesting research subject in its own right, it falls beyond the scope of this paper, focusing as we do on diurnal cycles over the mid-latitude WBCs. Furthermore, amplitudes and relative amplitudes of these diurnal precipitation cycles are weaker than those found over the Northern Hemisphere WBCs in summer (Fig. 2). Therefore, we focus our attention on the diurnal variations over the Gulf Stream and the Kuroshio in boreal summer, closely examining their spatiotemporal structures in the following sections. 
Fig. 4 Amplitudes of 24-h diurnal cycle (left) and mean rain rate (right) of precipitations over the Gulf Stream region in June (top), July (middle) and August (bottom). Gray areas in left panels are excluded from the analysis, because missing data rate due to presence of ice is larger than $20 \%$. Contours in each panel indicate SSTs with a contour interval of every $2{ }^{\circ} \mathrm{C}$ and dashed contours for 24 and $26{ }^{\circ} \mathrm{C}$ (a) Amplitude, JUN

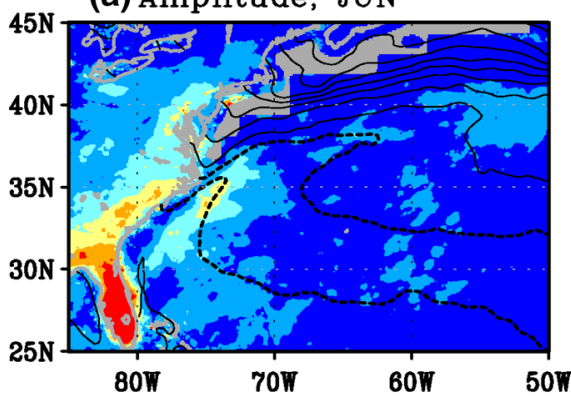

(c) Amplitude, JUL

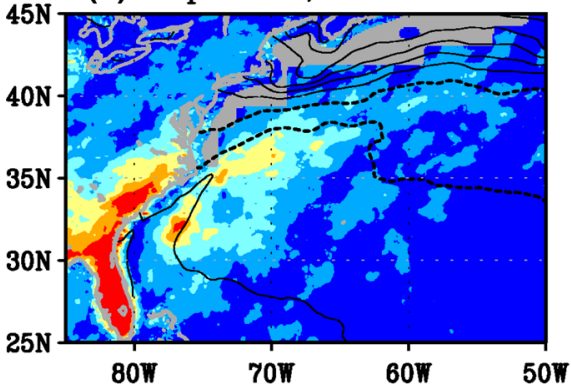

(e) Amplitude, AUG

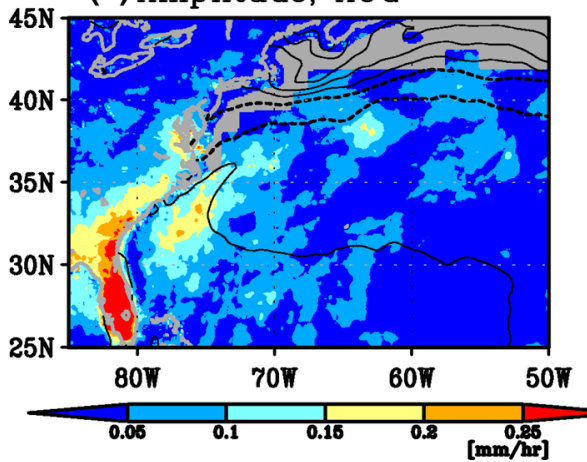

(b) Average, JUN

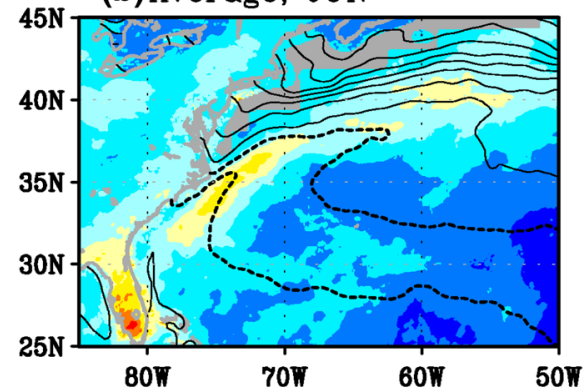

(d) Average, JUL

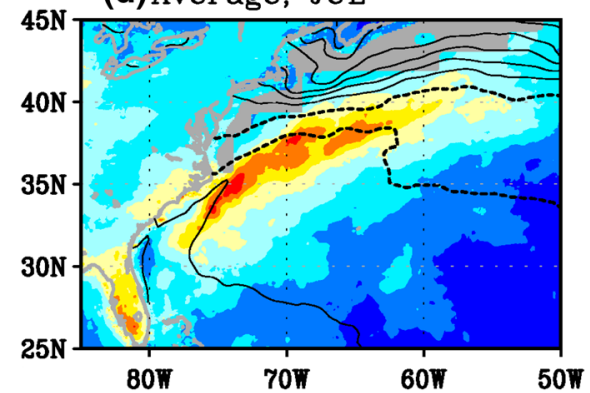

(f) Average, AUG

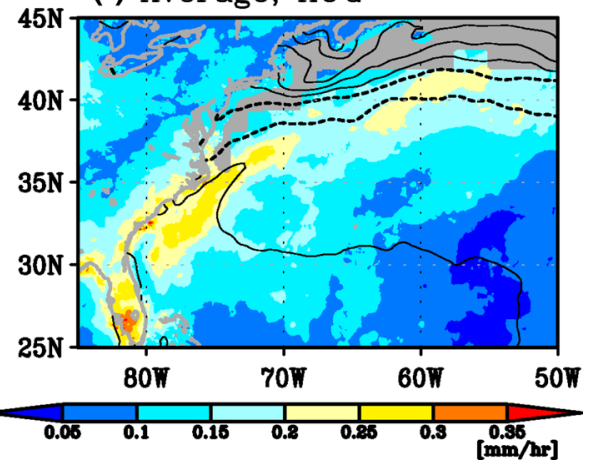

\section{Gulf Stream analysis}

Figure 4 shows climatological diurnal precipitation amplitudes, along with mean rain rate, over the Gulf Stream region in June, July and August. As reported by Minobe et al. (2010), who analyzed summer average precipitation, mean rain rate is enhanced over the Gulf Stream current axis. For convenient comparison, the spatial structure of the Gulf Stream is shown in Fig. 5. The monthly analysis indicates that the mean precipitation is especially strong in July, when the Gulf Stream rainband extends further east than in the other 2 months. The diurnal amplitudes are also strong over the Gulf Stream for all 3 months, with the maximum in July, but appear less well organized than the mean rain rate. The distribution of the strong diurnal amplitudes is also seen to be contracted westward compared with the spatial structure of the mean rain band. It is noteworthy that there are two local amplitude maxima in July; one occurs before the separation of the Gulf Stream from the coast (around $32^{\circ} \mathrm{N}, 77^{\circ} \mathrm{W}$ ), and the other after

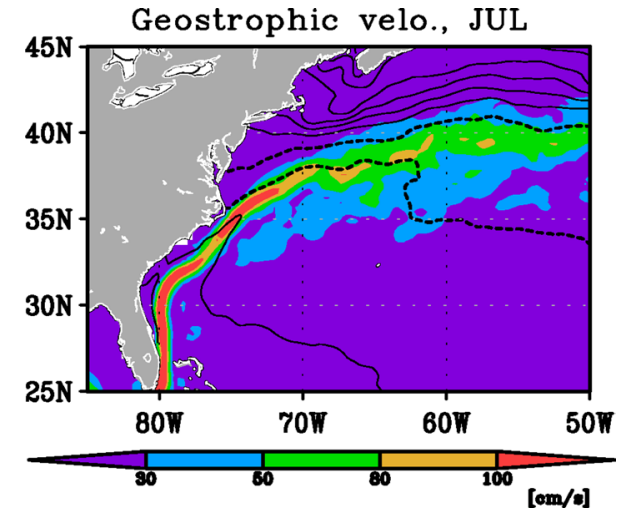

Fig. 5 Climatological absolute surface geostrophic velocity derived from satellite altimeter (color) and SSTs (contours) with a contour interval of every $2{ }^{\circ} \mathrm{C}$ and dashed contours for 24 and $26^{\circ} \mathrm{C}$ in July

it (around $36^{\circ} \mathrm{N}, 70^{\circ} \mathrm{W}$ ). The diurnal precipitation amplitudes over land are larger than those over the ocean, though magnitudes of mean rain rate over the ocean and land are 
(a) Relative Amplitude, JUL

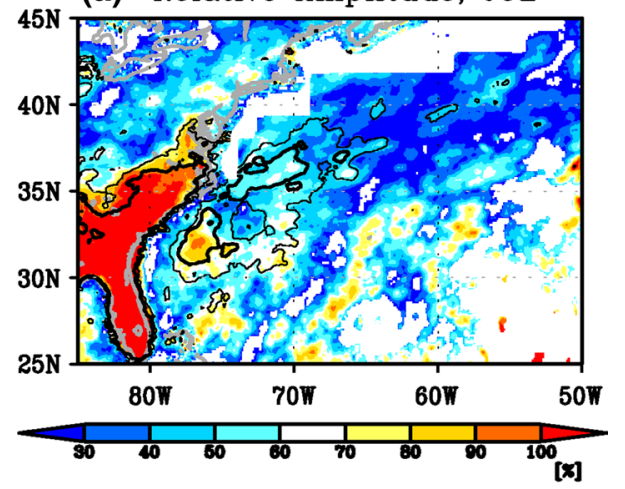

(b) Phase, JUL

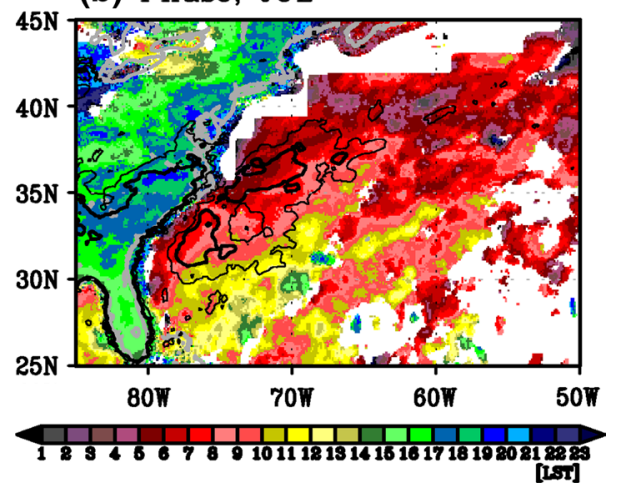

Fig. 6 a Relative amplitudes and $\mathbf{b}$ phases of the precipitation diurnal cycle over the Gulf Stream region in July. Phases shown by the time of maximum value of 24-h cycle in LST. Contours indicate 0.1 (thin contour) and $0.15 \mathrm{~mm} / \mathrm{h}$ (thick contour) of the amplitudes shown in Fig. 4c. White regions are either missing data, due to presence of ice being larger than $20 \%$, or the amplitudes shown in Fig. 4c are smaller than $0.02 \mathrm{~mm} / \mathrm{h}$

comparable in June and August or are larger over the ocean in July. Although the strength of mean Gulf Stream rainband and the amplitudes of diurnal cycle are strongest in July, their spatial structures are similar during the 3 months in summer. This is in marked contrast to the Kuroshio region, where month-to-month changes of spatial patterns are quite large as will be shown later. In the rest of this section, we describe diurnal variability over the Gulf Stream in July, when the maximal diurnal precipitation amplitude is observed.

The spatial structure of relative amplitudes is not clearly associated with the Gulf Stream (Fig. 6a). Rather, large relative amplitudes (50-90 \%) are found on and to the east of the Gulf Stream, over SSTs higher than about $26{ }^{\circ} \mathrm{C}$. This means that diurnal precipitation occurs somewhat ubiquitously in this area over warm SSTs. Consequently, the large diurnal amplitudes over the Gulf Stream reflect large mean precipitation, which is an aspect of atmospheric response to the Gulf Stream (Minobe et al. 2010), combined with high relative amplitudes over warm SSTs not limited to the Gulf
Stream. The relative amplitudes over land exceed $100 \%$ from the Florida peninsula to Cape Hatteras. The terrestrial high relative amplitudes suggest that precipitation occurs in narrower time periods than that expected from a sinusoidal wave. Indeed, this is the case, as will be shown below.

The phase of diurnal precipitation in July over the Gulf Stream (Fig. 6b) indicates that the diurnal precipitation peaks in the morning (about 5-11 LST). As mentioned previously, this early morning maximum is a common feature of diurnal precipitation cycles over the ocean (Yang and Slingo 2001; Dai et al. 2007; Kikuchi and Wang 2008). The phase generally increases seaward from the Gulf Stream, suggesting an southeastward phase propagation, with a phase speed in the range of $10-30 \mathrm{~m} / \mathrm{s}$. Seaward phase propagations of tropical diurnal precipitation cycles were reported in previous studies with speeds of $10-20 \mathrm{~m} / \mathrm{s}$, possibly due to gravity waves (Yang and Slingo 2001; Kikuchi and Wang 2008). For the aforementioned two amplitude maxima, the phase of the off-shore maximum slightly leads that of the near-shore maximum, indicating that precipitation occurs slightly earlier over the Gulf Stream after the separation than those before the separation with seaward propagation in respective regions. The phases over land indicate that the diurnal precipitation tend to peak in the late afternoon and early evening (about 15-19 LST), with phases in the Florida peninsula leading those along the coast north of $32^{\circ} \mathrm{N}$.

As noted above, the diurnal precipitation cycles over the Gulf Stream and over land have roughly opposite phases. In light of this, it is natural to consider whether the diurnal precipitation cycle over the ocean is tightly related to that over land. For example, is diurnal precipitation variability over the Gulf Stream strongly influenced by the diurnal precipitation over North America? Or are these two diurnal variations are essentially independent? In order to gain some insight into these questions, we conduct a lagcorrelation analysis using raw precipitation data. Here, lagcorrelations at each grid point are calculated with respect to the area-averaged precipitation time series. Two reference time series are chosen; one is taken for the aforementioned near-shore diurnal amplitude maximum over the Gulf Stream $\left(31-33^{\circ} \mathrm{N}, 78-76^{\circ} \mathrm{W}\right)$, and the other is taken from a region of strong diurnal precipitation cycle over land, along the same latitudinal band $\left(31-33^{\circ} \mathrm{N}, 83-81^{\circ} \mathrm{W}\right)$. The observed significance of the correlations is estimated based on lag-correlations of large-lags, where data can be assumed to be uncorrelated. More specifically, we calculate lag correlations with large lags from 7 to 14 days every $6 \mathrm{~h}$. In order to examine the significance at a specific grid point these large-lag correlations $\pm 5^{\circ}$ in latitudes and longitudes are collected. The collected correlations are then sorted in order their absolute correlations. If the observed absolute correlation is higher than top $5 \%$ of the collected large-lag 
Fig. 7 Lag correlation coefficients at each grid point along $32.05^{\circ} \mathrm{N}$ onto the reference area-averaged precipitation time series a in a region $83-81^{\circ} \mathrm{W}$, $31-33^{\circ} \mathrm{N}$ over land and $\mathbf{b}$ in a region $78-76^{\circ} \mathrm{W}, 31-33^{\circ} \mathrm{N}$ over the ocean. Positive lags indicate reference time series leading to data at each grid point
Fig. 8 a average, $\mathbf{b}$ amplitudes, c relative amplitudes and $\mathbf{d}$ phases of occurrence rate of high cloud estimated from OLR over the Gulf Stream region in July. Phases shown by the time of maximal value of 24-h cycle in LST. Contours in panels a and $\mathbf{b}$ are SSTs with a contour interval of $2{ }^{\circ} \mathrm{C}$, where dashed contours indicate 24 and $26^{\circ} \mathrm{C}$, whereas contours in panels $\mathbf{b}$ and $\mathbf{c}$ are diurnal amplitudes of 5 and $8 \%$

\section{Correlation, along $32.05 \mathrm{~N}$}

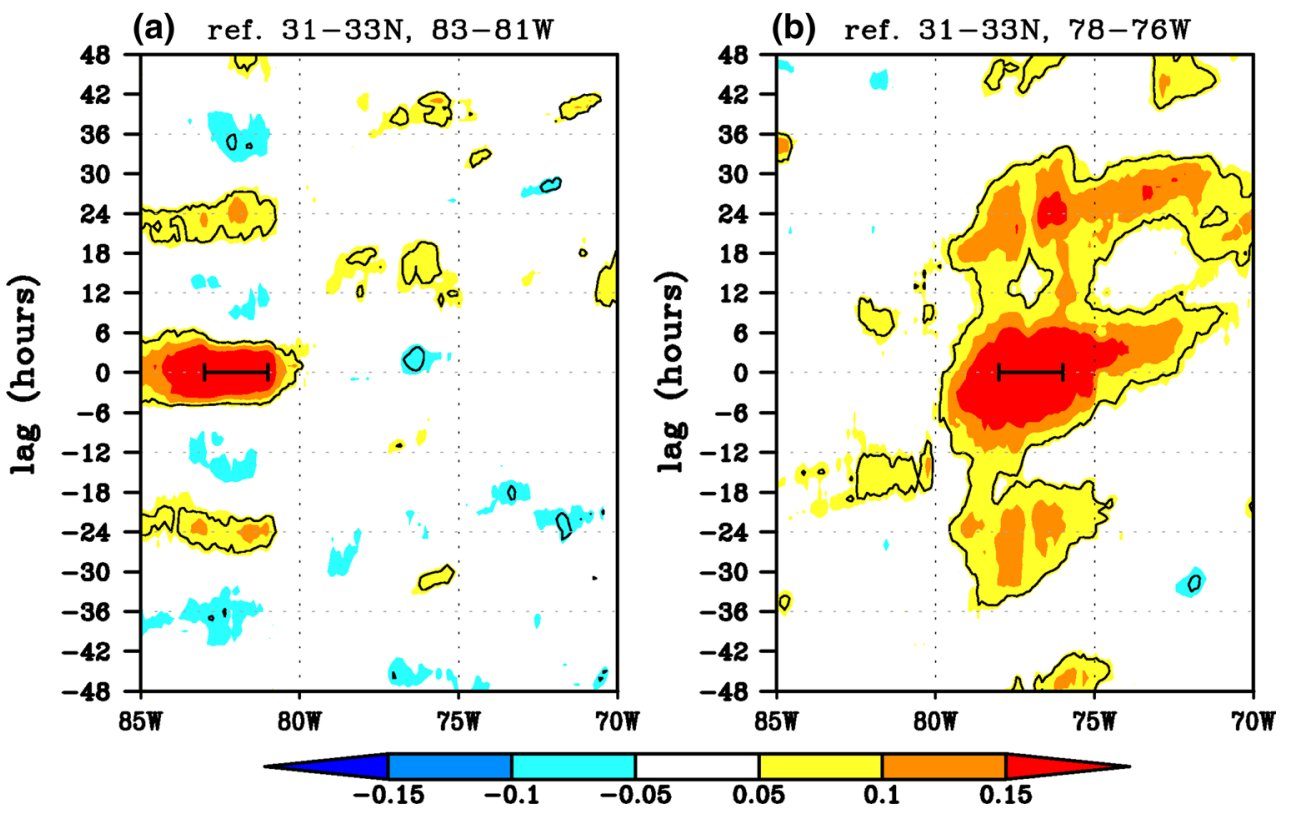

(a) Average, JUL

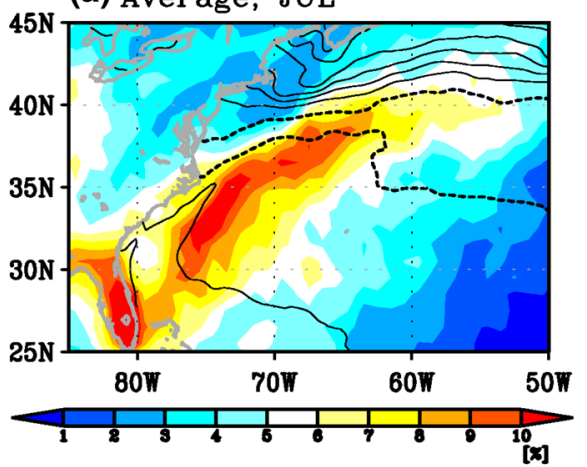

(c) Relative Amplitude, JUL

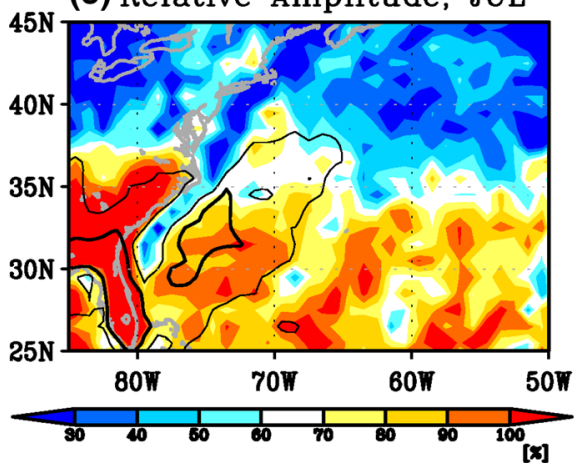

(b) Amplitude, JUL

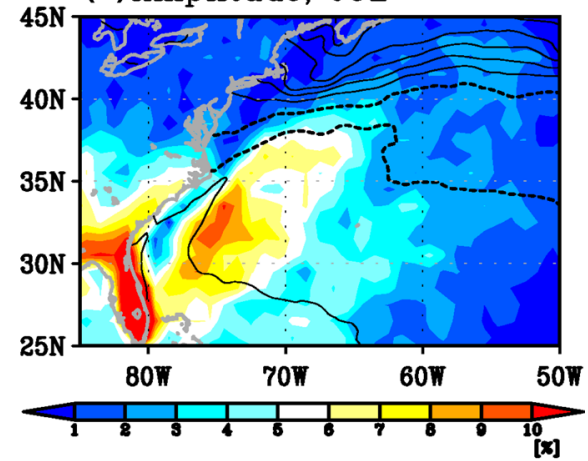

(d) Phase, JUL

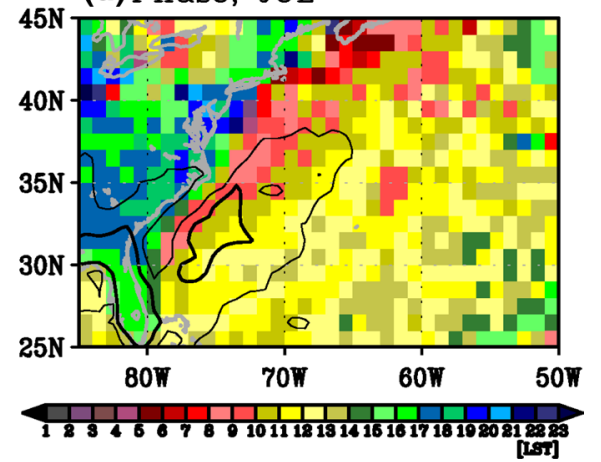

absolute correlations, the observed correlation is considered to be significant at the $5 \%$ significance level. This approach is better than the conventional theoretical estimation of significance, because raw hourly rain rate does not follow a Gaussian distribution, which is assumed for the theoretical estimation.
Figure 7 shows the lag-correlation at the central latitude of the reference time series $\left(32^{\circ} \mathrm{N}\right)$. The lag-correlations do not show a significant out-of-phase relation between the ocean and land with either the land or ocean reference time series, indicating that the out-of-phase relationship between their respective diurnal climatologies in Fig. $6 \mathrm{~b}$ 


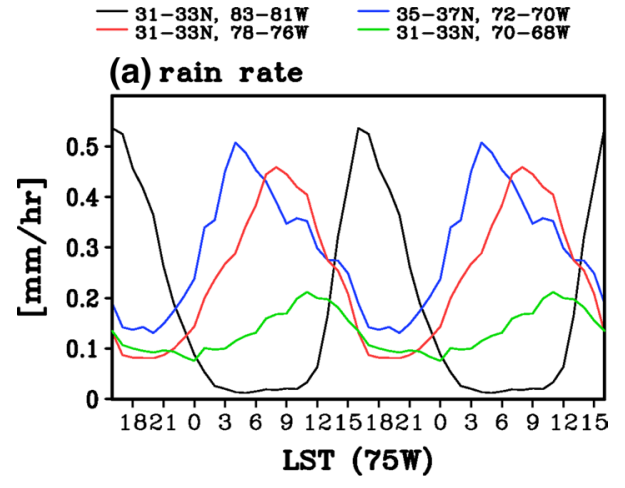

(b) high cloud frequency

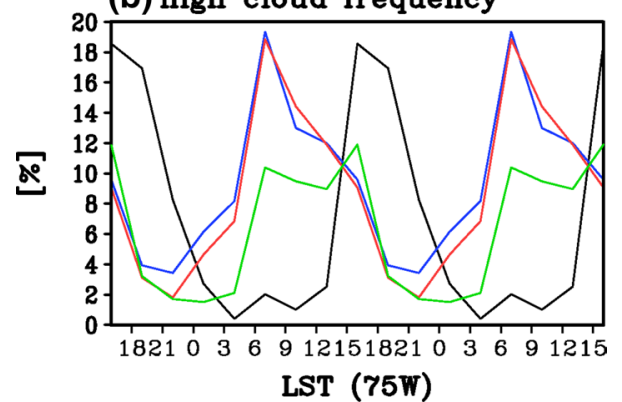

Fig. 9 Climatological time series of $\mathbf{a}$ rain rate and $\mathbf{b}$ high cloud frequency in July averaged over different box-areas. Black line is for a box over land $\left(31-33^{\circ} \mathrm{N}, 83-81^{\circ} \mathrm{W}\right)$, blue line is for a box for the off-shore diurnal precipitation maximum $\left(35-37^{\circ} \mathrm{N}, 72-70^{\circ} \mathrm{W}\right)$, red line is for a box for the near-shore diurnal precipitation maximum $\left(31-33^{\circ} \mathrm{N}, 76-78^{\circ} \mathrm{W}\right)$, and green line is for a box to the east of the near-shore maximum (east of the Gulf Stream) $\left(31-33^{\circ} \mathrm{N}\right.$, $\left.72-78^{\circ} \mathrm{W}\right)$

essentially arises independently. A weak land-leading relation is observed with +12 to 18 ( -18 to 12 ) h lags Fig. 7 a, b). Combined with the aforementioned afternoon and morning maxima of land and ocean diurnal precipitation, this relation means that occurrence of land-precipitation in one afternoon may slightly enhance the precipitation over the Gulf stream in next morning. Consistently, eastward propagation is seen in the lag-correlations over the ocean. The actual propagation direction is southeastward with the propagation speed about $5 \mathrm{~m} / \mathrm{s}$ (not shown). This propagation speed is slower than the phase velocity estimated from the phase distribution in Fig. 6b. Alliss and Raman (1995) suggested that wind advection can cause a similar lag relation in cloud fields. Another possible mechanism may be gravity wave propagation (Yang and Slingo 2001; Mapes et al. 2003), but the clarification of the responsible mechanism is a subject of future study. Another interesting point of Fig. 7 is that positive correlations over the ocean are persistent during $\pm 36 \mathrm{~h}$ lags with the ocean reference time series (Fig. 7b) probably related to synoptic scale variability, whereas correlations over land with the land reference time series does not show such persistent tendency but exhibit weak negative correlations around $\pm 12 \mathrm{~h}$ lags (Fig. 7a). This suggests that synoptic scale variability exhibits a stronger influence over the ocean than over land compared to diurnal cycles.

Diurnal variability is also seen in high-level clouds. Mean occurrence frequency of high-level clouds in July is enhanced along the Gulf Stream (Fig. 8a), consistent with a previous study (Minobe et al. 2008, 2010). Figure 8b shows that diurnal amplitudes of the occurrence frequency are large over the Gulf Stream west of $65^{\circ} \mathrm{W}$, consistent with the diurnal precipitation amplitudes shown in Fig. 4c. The relative amplitudes of high cloud frequency (Fig. 8c) are generally larger than those of precipitations (Fig. 6a), as shown by much wider area of relative amplitudes greater than $90 \%$ in the former. This indicates that the diurnal cycle is more apparent in high cloud frequency than in precipitation, suggesting that deep convection plays an important role in diurnal cycles. The phases for high cloud frequency (Fig. 8d) are delayed compared to those of the precipitation (Fig. 6b) by 1-2 h, but otherwise the overall spatial phase structure is quite consistent with that of the precipitation, including the southeastward phase propagation noted above. The time lag between the precipitation and high cloud occurrence may reflect the fact that the high clouds can be persistent for hours after the convection maximum (e.g., Gray and Jacobson 1977; Rickenbach et al. 2008). The pattern of amplitudes and phases of high-cloud frequency are generally consistent with those of high-cloud amount of ISCCP D2 dataset, though collocation between the amplitude maximum with the Gulf Stream current axis and southeastward phase propagations are not well resolved in the latter dataset due to coarse resolution (not shown).

Diurnal cycles may involve other components than the 24-h Fourier component, and hence it is interesting to see diurnal climatology time series at some locations. Figure 9a shows diurnal precipitation climatology time series at four locations (rectangular regions of $2^{\circ} \times 2^{\circ}$ ). ${ }^{1}$ These regions are the aforementioned off-shore and near-shore diurnal amplitude maxima (blue and red curves, respectively), east of the Gulf Stream (green curve), and on land (black curve). The time series for the amplitude maxima exhibit relatively narrow peaks and wide troughs. Consistent with the large relative amplitudes described above, the difference of magnitude between the peak and the trough are remarkable. The diurnal maximum rain rate is more than four times (three times) larger than the diurnal minimum at the near-shore (off-shore) amplitude maximum. The

\footnotetext{
${ }^{1}$ Animation of diurnal climatology of rain rate over the Gulf Stream region in July (and also over the Kuroshio region in June examined in Sect. 5) is found at author's home page, http://www.sci.hokudai.ac.jp/ $\sim$ minobe/animation/diurnal_precip_WBCs/.
} 
Fig. 10 Same as Fig. 4, but for the Kuroshio region in May (top), June (middle) and July (bottom). Note that the colorscale values are larger than those in Fig. 4

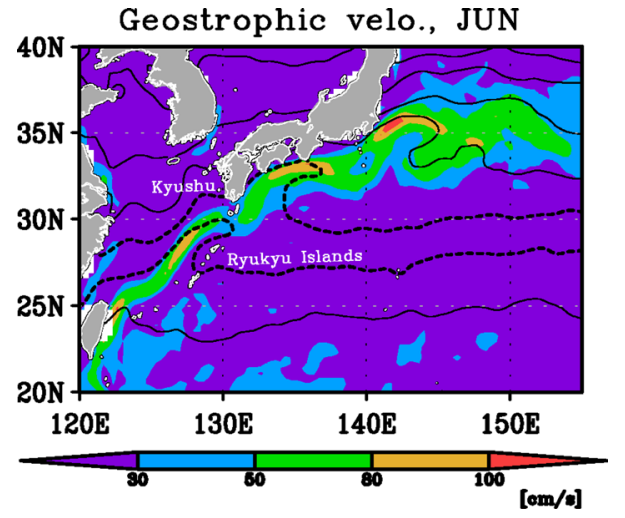

Fig. 11 Same as Fig. 5, but for the Kuroshio region. Kyushu Island and Ryukyu Islands are denoted

diurnal precipitation peak occurs at $4 \mathrm{LST}$ for $75^{\circ} \mathrm{W}$ for the off-shore maximum and at 8 LST for the near-shore maximum, and time series in regions east of the Gulf Stream
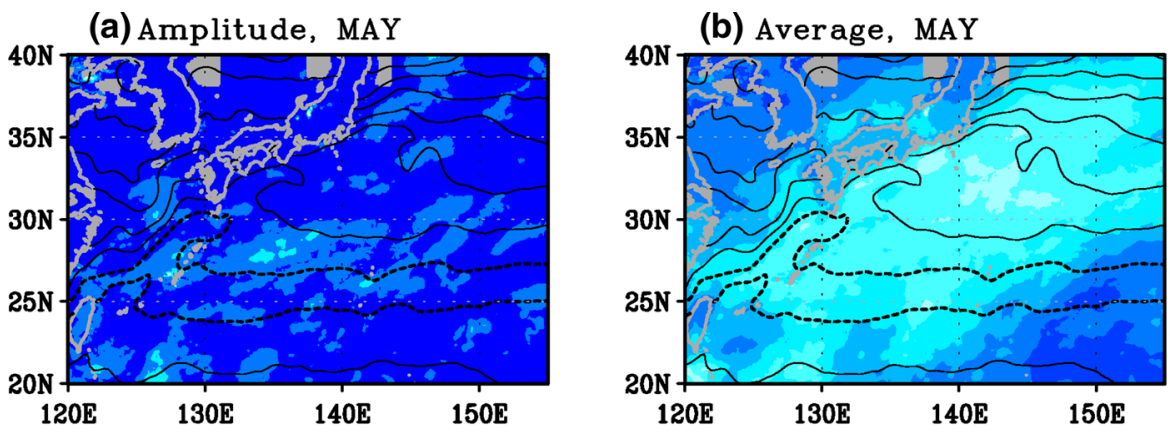

(c) Amplitude, JUN

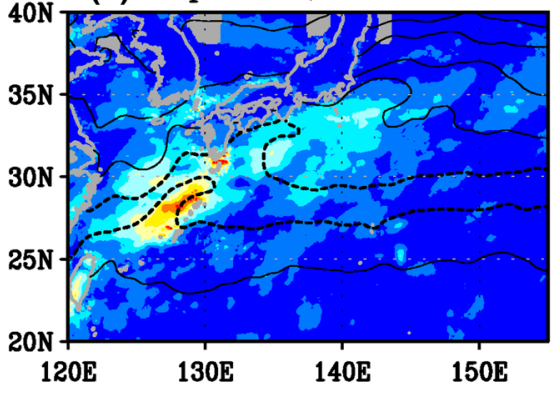

(d) Average, JUN

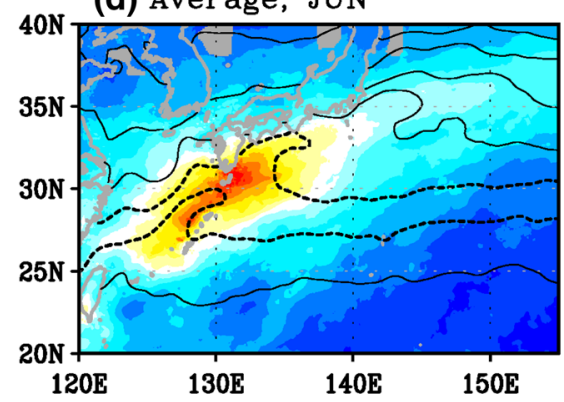

(f) Average, JUL

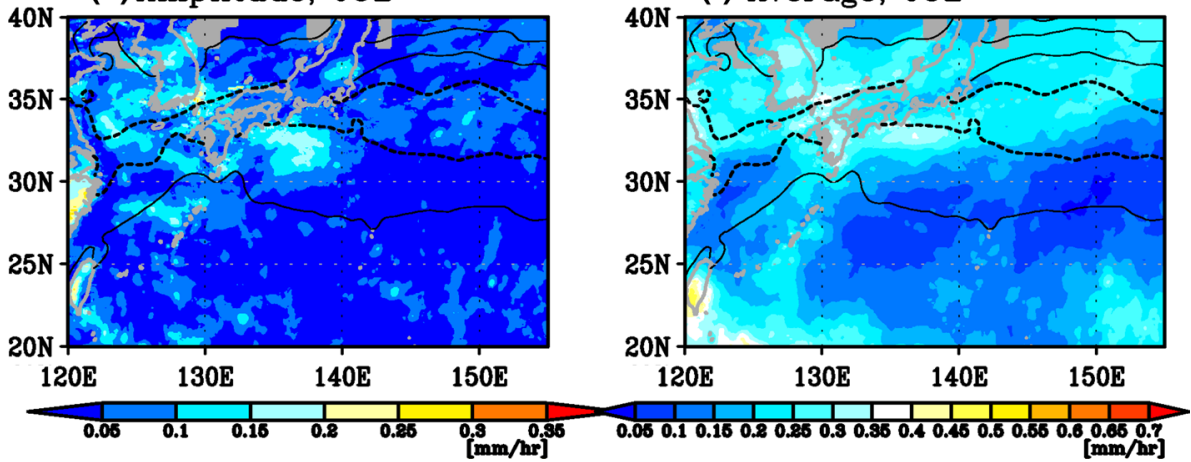


(a) Relative Amplitude, JUN

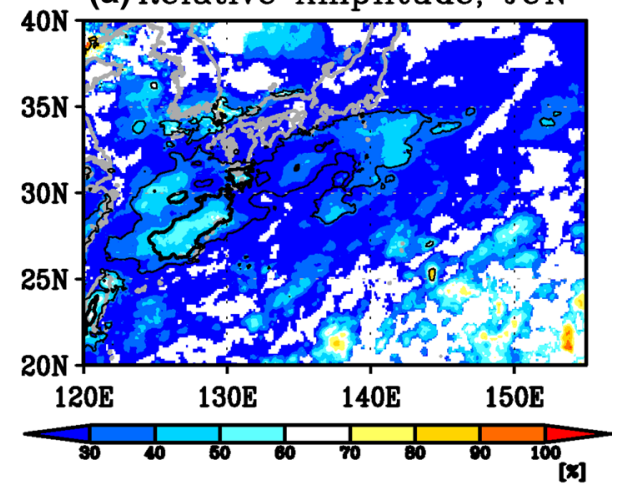

(b) Phase, JUN

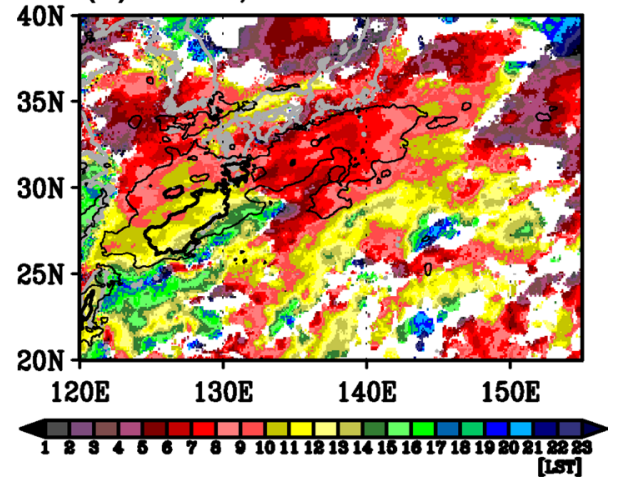

Fig. 12 Same as Fig. 6, but for the Kuroshio region in June. Contours indicate 0.1 (thin contour) and $0.2 \mathrm{~mm} / \mathrm{h}$ (thick contour) of the amplitude shown in Fig. 10c

Fig. 13 Same as Fig. 8, but for the Kuroshio region. Note that the color-scale values for panel a are larger than those for Fig. 8a (a) Average, JUN

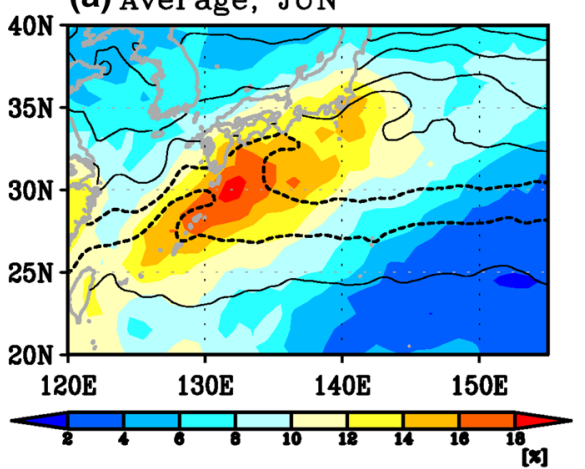

(c) Relative Amplitude, JUN

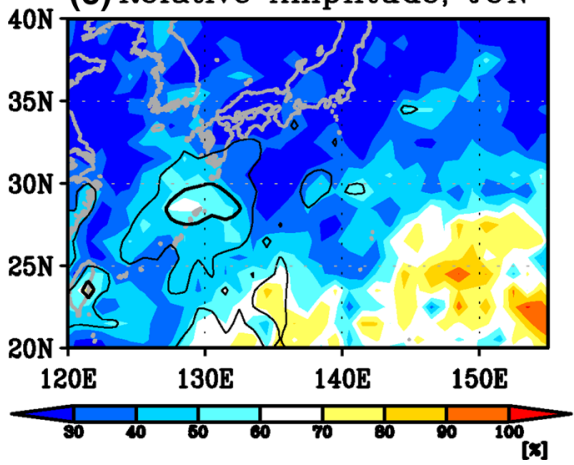

differences from the diurnal cycles over the Gulf Stream described in the previous section. An important environmental factor in the Kuroshio region is the presence of the Baiu-Meiyu rain and cloud bands as introduced in Sect. 1. Baiu-Meiyu rainband typically begins in the middle of May, slowly moves northwards, and disappears in July as is somewhat reflected in the monthly mean rain rate (Fig. 10b, d, f). For example, the maximal rain rate in June to the south of the Kyushu is embedded in the large-scale Baiu-Meiyu rain/cloud band extending from southern China to the east of Japan, consistent with Fig. 3 of Sasaki et al. (2012), and relatively strong precipitation around $32-40^{\circ} \mathrm{N}$ in July is also associated with the Baiu-Meiyu rain band. Another important factor is that a vast land mass, similar to North America to the west of the Gulf Stream, does not exist around the Kuroshio. Therefore, a comparison of diurnal cycles between the two regions can give us some insight into the nature of the diurnal cycles over the WBCs. Again for convenient comparison, the surface geostrophic currents along with SSTs in June are shown in Fig. 11.

The strongest diurnal cycle is found in June over the Kuroshio in the East China Sea (Fig. 10c). In this month, mean rain rate is also the strongest, consistent with Sasaki et al. (2012) (Fig. 10d). The maximal diurnal amplitude is as high as $0.36 \mathrm{~mm} / \mathrm{h}$ to the west of Ryukyu Islands, which is about $30 \%$ larger than the maximum amplitude during July in the North Atlantic $(0.28 \mathrm{~mm} / \mathrm{h})$, and this is 


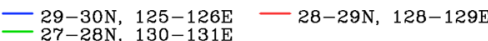

(a) rain rate

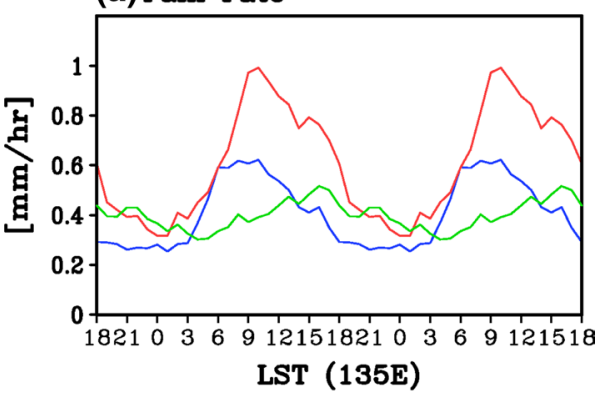

(b) high cloud frequency

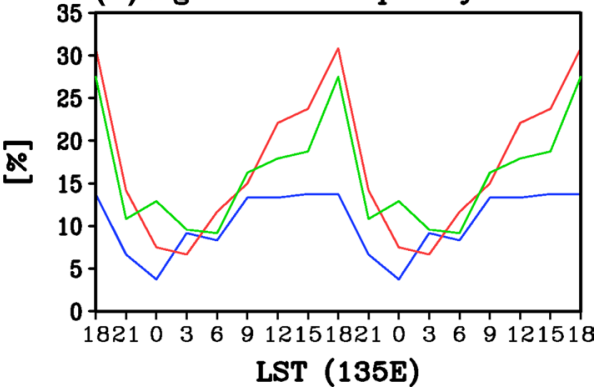

Fig. 14 Same as Fig. 9, but for the Kuroshio region in June. The blue line is for a box for the off-shore diurnal precipitation maximum (29$\left.30^{\circ} \mathrm{N}, 125-126^{\circ} \mathrm{E}\right)$, red line is for a box for the near-shore diurnal precipitation maximum $\left(28-29^{\circ} \mathrm{N}, 128-129^{\circ} \mathrm{W}\right)$, and green line is for a box to the east of the near-shore maximum $\left(27-28^{\circ} \mathrm{N}, 130-131^{\circ} \mathrm{W}\right)$, corresponding to the west-northwest, middle, and east-southeast regions of the diurnal precipitation amplitude maximum in Fig. 10c, respectively

the largest diurnal precipitation amplitude over the midlatitude global oceans in all calendar months. In June, the secondary amplitude maximum is seen to the south of Kyushu, and two patches of relatively high amplitude are found in the North Pacific to the south of Japan. These spatial features are not seen in the average precipitation, which is more smoothly distributed from the East China Sea to the North Pacific. The strong diurnal precipitations in the East China Sea are limited to June and not found in either May or July (Fig. 10a, c, e). This is in contrast to the diurnal cycle over the Gulf Stream, which exhibits similar spatial structures during all summer months. The rapid month to month transition of diurnal precipitations is closely related to the mean precipitation change, which is governed by the northward migration of the Baiu-Meiyu rainband (e.g., Wang and LinHo 2002). In the rest of this section, we closely examine diurnal cycles over the Kuroshio in June.

Despite the strong diurnal precipitation amplitudes over the Kuroshio in the East China Sea, the relative amplitudes in this region are slightly smaller than those over the Gulf Stream (Fig. 12a). This is because mean precipitation over the Kuroshio is much larger than that over the Gulf Stream, and the maximum mean rain rate of the former region is about two times larger than the latter (Note that maximum value for the color scale of Fig. 10d is two times larger than that in Fig. 4d). The strong mean precipitation is associated with the large-scale Baiu-Meiyu rain band, in which enhanced precipitation due to the Kuroshio is located over the East China Sea (Sasaki et al. 2012). The Baiu-Meiyu rain band itself does not generally exhibit a strong diurnal cycle, as shown by weak relative amplitude south of Japan (Fig. 12a). These results indicate that the combination of the Kuroshio's impact on the diurnal precipitation cycle and large-scale Baiu-Meiyu rainband with a weak diurnal cycle, is important for understanding the diurnal variations over the Kuroshio in the East China Sea.

Figure $12 \mathrm{~b}$ shows the phase distribution of the 24-h components of precipitation over the Kuroshio region. Peak time for large diurnal amplitudes (say $0.2 \mathrm{~mm} / \mathrm{h}$ or more) is 10-13 LST, few hours later than that over the Gulf Stream. Also, around the large diurnal amplitudes, phases indicate southeastward increase with the speeds of $10-20 \mathrm{~m} / \mathrm{s}$. The propagation direction is roughly the same as that in the Gulf Stream region, but the propagation speed over the Kuroshio is somewhat slower.

Diurnal variability is also found in high cloud occurrence in June over the Kuroshio. Mean high cloud occurrence (Fig. 13a) shows a similar spatial pattern to that of precipitation (Fig. 10d). The magnitude is again much larger than that over the Gulf Stream, consistent with precipitation. Diurnal amplitudes of high cloud occurrence exhibits a maximum over the Ryukyu Islands (Fig. 13b), roughly collocated with high amplitude region of diurnal precipitation variations. However, the location of the maximum high cloud amplitude is slightly shifted to the east compared to the precipitation maximum, which could be due to anvils advected by background westerlies. The maximum amplitude $(11 \%)$ is similar to the maximum value over the Gulf Stream (10\%). Relative amplitudes over the Kuroshio are, on the other hand, much smaller than those over the Gulf Stream (Figs. 8c, 13c), due to the larger mean high cloud occurrence rates. Therefore, for both the precipitation and high cloud occurrence, the diurnal component associated with the Kuroshio and the Gulf Stream have similar magnitudes, but the superimposed large-scale BaiuMeiyu rain band without strong diurnal variability results in small relative amplitudes over the Kuroshio region.

Phases of the 24-h component of high cloud occurrence rate exhibit peaks in the early afternoon (12-16 LST) over regions of strong amplitudes, straddling the East China Sea and the western North Pacific (Fig. 13d). In this region, phases of high cloud occurrence are delayed by $2-3 \mathrm{~h}$ compared with those of precipitation, and this delay is slightly longer than is found over the Gulf Stream. An southeastward phase propagation is found for the large amplitude 
(a) Gulfstream

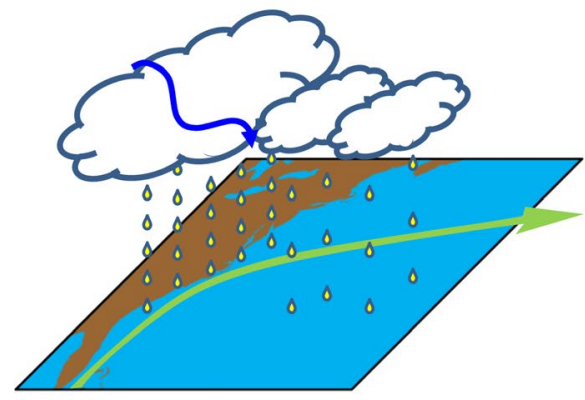

(b) Kuroshio

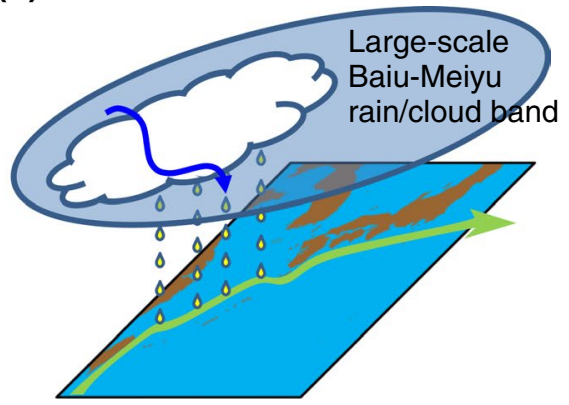

Fig. 15 Schematics of some essential features of the diurnal precipitation and high cloud cycles over the Gulf Stream (a) and the Kuroshio in the East China Sea (b). The Gulf Stream and the Kuroshio are indicated by the green arrows. Diurnally modulated precipitations and high clouds are shown by rain drops and cloud shapes, respectively. Oval in panel b indicates large-scale Biu-Meiyu rain/ cloud band. The wavy arrows indicate southeastward phase propa-

region, consistent with precipitation. The phase and amplitude distributions of high-cloud frequency derived from OLR data are generally consistent with those of high-cloud amount of ISCCP D2 dataset (not shown).

Figure 14 shows diurnal climatology time series of precipitation and high-cloud occurrence rate at three locations around the diurnal precipitation amplitude maximum. Consistent with the aforementioned phase propagation, the time at which the diurnal precipitation peak occurs is increasingly delayed in the southeastward direction (Fig. 14a). Interestingly, the peak of high-cloud frequency in the region of the precipitation amplitude maximum occurs in evening, $18 \mathrm{LST}$, delayed by about $8 \mathrm{~h}$ compared to the precipitation peak (Fig. 14b). The reason why the peak time difference in the East China Sea is much larger than that over the Gulf Stream is not known to the authors, and is a potential subject of future study.

\section{Discussion and conclusions}

Diurnal variations over the mid-latitude oceans are analyzed using an hourly, satellite-derived precipitation dataset (GSMaP MVK ver. 5) and 3-hourly OLR data from the SRB project. Previous studies have also described diurnal precipitation cycles, including the mid-latitude oceans (e.g., Dai et al. 2007), although the link between diurnal precipitation cycles and WBCs is analyzed comprehensively in this study. It is found that over mid-latitude oceans, poleward of $25^{\circ} \mathrm{N} / \mathrm{S}$, strong diurnal cycles occur over the Northern Hemisphere WBCs, i.e., the Gulf Stream and the Kuroshio, in the boreal summer season (Fig. 2). No prominent diurnal precipitation is found over the WBCs in the Southern Hemisphere the whole year round (Figs. 2, 3). gation of diurnal precipitations and clouds. In both regions, strong diurnally modulated precipitation and cloud cycles are found over the Gulf Stream and the Kuroshio, with southeastward phase propagation. Somewhat similar diurnal cycles are found to the east of the Gulf Stream with weaker amplitudes. The strong diurnal cycle over the Kuroshio is embedded in large-scale Baiu-Meiyu rainband, which does not have prominent diurnal cycles

There are some common features but also differences in the diurnal cycles between the regions over the Gulf Stream and the Kuroshio. In both regions, maximum amplitudes of diurnal precipitation occur roughly over the current axes with a pattern contracted westward compared with the rainbands, more specifically, just before and after the separation at the Cape Hatteras for the Gulf Stream (Fig. 4) and west of Ryukyu Islands in the East China Sea for the Kuroshio (Fig. 10). The maximum amplitudes are slightly larger over the Kuroshio than over the Gulf Stream. The diurnal phases commonly exhibit southeastward propagation, with peak times for the large amplitudes being from early to late morning (5-11 LST) for the Gulf Stream (Fig. 6b) and from late morning to noon (10-13 LST) over the Kuroshio in the East China Sea (Fig. 12b). Occurrence frequencies of high clouds exhibit diurnal cycles consistent with those of the precipitation. The relative amplitudes of high cloud occurrence are larger than those of precipitation, suggesting that the diurnal precipitation is mainly due to deep convection, consistent with studies of tropical diurnal precipitation over the oceans (e.g., Janowiak et al. 1994; Yang and Slingo 2001). Near the Gulf Stream, diurnal precipitation cycles over North America are roughly $180^{\circ}$ out-of-phase of those over the ocean (Fig. 6b). The lag-correlation analysis shows that a direct link between oceanic and terrestrial diurnal cycles is not strong (Fig. 7), if it exists at all, and thus they probably originate different physical mechanisms.

Major differences between the diurnal cycles over the Gulf Stream and those over the Kuroshio are likely to be associated with the presence of large-scale Baiu-Meiyu rainband, consistent with Sasaki et al. (2012) who suggested that local atmospheric response to the Kuroshio in the East China Sea is embedded in large-scale BaiuMeiyu rainband. The seasonal northward migration of 
Baiu-Meiyu rainband, associated with development of the subtropical high, yields substantially different diurnal precipitations from a month to month. The prominent diurnal precipitation is limited to June (Fig. 10), the peak month of the Baiu-Meiyu precipitation over the East China Sea. On the other hand, the spatial patterns of the diurnal and mean precipitation over the Gulf Stream do not change much from June to August, with the maximum amplitude occurring during July (Fig. 4). The maximum mean rain rate over the Kuroshio in the East China Sea and south of Japan in June is roughly two times larger than that over the Gulf Stream in July (Figs. 4, 10). The large mean rain rate associated with the Baiu-Meiyu rainband results in smaller relative amplitudes over the Kuroshio than are found over the Gulf Stream (Figs. 6a, 12a). The large relative amplitudes of precipitation and high cloud occurrence are widely distributed over warm SSTs in the North Atlantic. Large relative amplitudes over the Kuroshio region, however, are only found in the vicinity of the Kuroshio itself. This does not necessary mean that diurnal precipitations do not occur over a wider area, but if they occur, they may be obscured by the large-scale Baiu-Meiyu rainband in which prominent diurnal cycles are absent. Major features of the diurnal precipitation and high cloud cycles are summarized in Fig. 15.

The diurnal cycles are likely to be closely associated with the deep heating mode of the atmospheric response to the WBCs. The spatial and seasonal distributions of the strong deep heating mode found in previous studies (Minobe et al. 2010; Sasaki et al. 2012) and those of diurnal precipitation appear to be similar to one another. This is not surprising, because as discussed in Sect. 1, it is known that diurnal precipitation variability is strong in the tropics, and the deep heating mode is a tropical-like atmospheric response to ocean fronts over SSTs warmer than $24-26{ }^{\circ} \mathrm{C}$ (Minobe et al. 2010). It is noteworthy that diurnal precipitation variability over the Gulf Stream and the Kuroshio has higher relative amplitudes than those over most of the tropics. Furthermore, contributions of diurnal cycles to average rain rate are larger over the WBCs than in the ITCZ and SPCZ, and thus diurnal variability can be an important agent for producing in mean precipitations in the WBC regions. Consequently, it is strongly suggested that the diurnal precipitation and cloud cycles are intrinsic and important aspects of the deep heating mode.

A natural question is what mechanism is responsible for the diurnal cycles over the Gulf Stream and the Kuroshio? This is an open question not only for the diurnal cycles over these WBCs but also for diurnal cycles over the tropical oceans, which have been much more widely studied (e.g., Dai et al. 2007; Kikuchi and Wang 2008). Yang and Smith (2006) summarized twelve proposed mechanisms for diurnal precipitation. Among these mechanisms, a morning maximum may be produced by two mechanisms. One mechanism is static radiation convection, in which radiative cooling from the top of clouds during the night time destabilizes the upper cloud, and thus increases convection and precipitation (e.g., Kraus 1963; Randall et al. 1991). Another mechanism is static radiation convection with enhanced moistening (Tao et al. 1996; Sui et al. 1997). In this mechanism, enhanced night time radiative cooling increases humidity, and thus amplifies condensation and precipitation. It is interesting to examine whether one of these, or other, mechanisms play a role over the WBCs in future study. The southeastward phase propagations observed over the Gulf Stream and East China Sea are somewhat reminiscent of previously reported seaward phase propagations of diurnal precipitation cycles in the tropics (Yang and Slingo 2001; Kikuchi and Wang 2008). It is suggested that the tropical seaward phase propagation is due to gravitation waves, which can generated by topographic effects (Mapes et al. 2003) or land convection (Zuidema 2003). Another possible mechanism for the phase propagation is advection by background winds, as has been suggested for diurnal cloud developments over the Gulf Stream region (Alliss and Raman 1995).

In order to identify the mechanism, atmospheric numerical models should be useful. Indeed, Fig. 6 of Dirmeyer et al. (2012) shows that enhanced diurnal precipitation over the Gulf Stream are somewhat reproduced by several numerical models. However, in that paper, which focuses on diurnal precipitations over North America, phases over the North Atlantic are masked out due to small amplitudes for most of models, and thus it is not clear whether these models can reproduce the observed phase distribution. A model whose phase distribution over the western North Atlantic was shown in that paper is the Nonhydrostatic ICosahedral Atmospheric Model (NICAM), which exhibits reasonable phase difference between the off-shore region and near-shore region along the Gulf Stream, but the seaward phase increase is not seen (Fig. 5 in their paper). Nevertheless, a reasonable step for identifying the mechanism forthe diurnal cycle in real world may be to examine these and other model outputs to assess the degree to which they can reproduce the diurnal cycles and to then identify the responsible mechanisms.

It should be worth noting that successfully capturing the diurnal cycle in numerical atmospheric models can be essential in producing mean realistic distributions of precipitation and thus atmospheric heating. Moisture used for the precipitation over the Gulf Stream and the Kuroshio is supplied by the local evaporation and moisture transport from the south along the west flank of the subtropical high (Minobe et al. 2010; Sasaki et al. 2012). The diurnal cycle can thus play an essential role in turning the moisture into precipitation in the relevant locations. If this hypothesis is correct, numerical 
model tunings, which primarily focus on the diurnal cycle, can improve not only the diurnal cycle itself but also mean precipitation distributions. This hypothesis can be examined by changing parameterizations or radiation forcings in a model. According to this hypothesis, the diurnal cycle canbe important not only in the context of weather, but also from a climate perspective. Consequently, the diurnal cycles over the Gulf Stream and the Kuroshio, which may be an intrinsic aspect of the deep heating mode, link the ocean and the atmosphere, and also possibly weather and climate.

Acknowledgments Many thanks for Dr. C. O'Reilly for comments on the English and also on the science, and for two anonymous reviewers for their helpful and constructive comments. This work was supported by the Japan Society for the Promotion of Science (Grantin-Aid for Scientific Research 22106008 and 22244057).

Open Access This article is distributed under the terms of the Creative Commons Attribution License which permits any use, distribution, and reproduction in any medium, provided the original author(s) and the source are credited.

\section{References}

Alexander MA, Scott JD (1997) Surface flux variability over the North Pacific and North Atlantic Oceans. J Clim 10(11):29632978. doi:10.1175/1520-0442(1997)010<2963: sfvotn>2.0.co;2

Alliss RJ, Raman S (1995) Diurnal-variations in-cloud frequency over the Gulf-Stream locale. J Appl Meteorol 34(7):1578-1594. doi:10.1175/1520-0450(1995)034<1578:dvicfo>2.0.co;2

Booth JF, Thompson L, Patoux J, Kelly KA, Dickinson S (2010) The signature of the midlatitude tropospheric storm tracks in the surface winds. J Clim 23(5):1160-1174. doi:10.1175/2009jcli3064.1

Booth JF, Thompson L, Patoux J, Kelly KA (2012) Sensitivity of midlatitude storm intensification to perturbations in the sea surface temperature near the Gulf Stream. Mon Wea Rev 140(4):12411256. doi:10.1175/mwr-d-11-00195.1

Brayshaw DJ, Hoskins B, Blackburn M (2008) The storm-track response to idealized SST perturbations in an aquaplanet GCM. J Atmos Sci 65(9):2842-2860. doi:10.1175/2008jas2657.1

Brayshaw DJ, Hoskins B, Blackburn M (2011) The basic ingredients of the North Atlantic storm track. Part II: sea surface temperatures. J Atmos Sci 68(8):1784-1805. doi:10.1175/2011jas3674.1

Chelton DB, Xie SP (2010) Coupled ocean-atmosphere interaction at oceanic mesoscales. Oceanography 23(4):52-69

Chelton DB, Schlax MG, Freilich MH, Milliff RF (2004) Satellite measurements reveal persistent small-scale features in ocean winds. Science 303(5660):978-983. doi:10.1126/science.1091901

Czaja A, Blunt N (2011) A new mechanism for ocean-atmosphere coupling in midlatitudes. Q J Roy Meteor Soc 137(657):10951101. doi:10.1002/qj.814

Dai A, Lin X, Hsu K-L (2007) The frequency, intensity, and diurnal cycle of precipitation in surface and satellite observations over low- and mid-latitudes. Clim Dyn 29(7-8):727-744. doi:10.1007/ s00382-007-0260-y

Dirmeyer PA, Cash BA, Kinter JL, Jung T, Marx L, Satoh M, Stan C, Tomita H, Towers P, Wedi N, Achuthavarier D, Adams JM, Altshuler EL, Huang BH, Jin EK, Manganello J (2012) Simulating the diurnal cycle of rainfall in global climate models: resolution versus parameterization. Clim Dyn 39(1-2):399-418. doi:10.1007/s00382-011-1127-9
Gray WM, Jacobson RW (1977) Diurnal-variation of deep cumulus convection. Mon Wea Rev 105(9):1171-1188. doi:10.1175/1520 0493(1977)105<1171:dvodcc>2.0.co;2

Hayasaki M, Kawamura R, Mori M, Watanabe M (2013) Response of extratropical cyclone activity to the Kuroshio large meander in northern winter. Geophys Res Lett 40(11):2851-2855. doi: $10.1002 /$ grl.50546

Hoskins BJ, Hodges KI (2002) New perspectives on the Northern Hemisphere winter storm tracks. J Atmos Sci 59(6):1041-1061. doi:10.1175/1520-0469(2002)059<1041:Npotnh>2.0.Co;2

Hoskins BJ, Valdes PJ (1990) On the existence of storm-tracks. J Atmos Sci 47(15):1854-1864. doi:10.1175/1520-0469(1990)047 $<1854$ :Oteost $>2.0$. Co; 2

Hoskins BJ, McIntyre ME, Robertson AW (1985) On the use and significance of isentropic potential vorticity maps. Q J Roy Meteor Soc 111(470):877-946. doi:10.1256/smsqj.47001

Huffman GJ, Adler RF, Bolvin DT, Gu GJ, Nelkin EJ, Bowman KP, Hong Y, Stocker EF, Wolff DB (2007) The TRMM multisatellite precipitation analysis (TMPA): quasi-global, multiyear, combined-sensor precipitation estimates at fine scales. J Hydrometeorol 8(1):38-55. doi:10.1175/jhm560.1

Inatsu M, Hoskins BJ (2004) The zonal asymmetry of the Southern Hemisphere winter storm track. J Clim 17(24):4882-4892. doi:1 $0.1175 /$ jcli-3232.1

Inatsu M, Mukougawa H, Xie SP (2003) Atmospheric response to Zonal variations in midlatitude SST: transient and stationary eddies and their feedback. J Clim 16(20):3314-3329. doi:10.1175/1520-0442(2003)016<3314:artzvi>2.0.co;2

Janowiak JE, Arkin PA, Morrissey M (1994) An examination of the diurnal cycle in oceanic tropical rainfall using satellite and in situ data. Mon Wea Rev 122(10):2296-2311. doi:10.1175/1520-0493 (1994)122<2296:aeotdc >2.0.co;2

Joyce TM, Kwon Y-O, Yu L (2009) On the relationship between synoptic wintertime atmospheric variability and path shifts in the Gulf Stream and the Kuroshio Extension. J Clim 22(12):31773192. doi:10.1175/2008jcli2690.1

Kikuchi K, Wang B (2008) Diurnal precipitation regimes in the global tropics. J Clim 21(11):2680-2696. doi:10.1175/2007jcli2051.1

Kraus EB (1963) The diurnal precipitation change over the sea. J Atmos Sci 20(6):551-556. doi:10.1175/1520-0469(1963)020<0551:tdpcot> 2.0.co;2

Kubota M, Tomita H (2007) The present state of the J-OFURO airsea interaction data product. Flux News, WCRP

Kuo YH, Shapiro MA, Donall EG (1991) The interaction between baroclinic and diabatic processes in a numerical-simulation of a rapidly intensifying extratropical marine cyclone. Mon Wea Rev 119(2):368-384. doi:10.1175/1520-0493(1991)119<0368:tibbad $>2.0 . \operatorname{co} ; 2$

Kuwano-Yoshida A, Minobe S, Xie S-P (2010) Precipitation response to the Gulf Stream in an atmospheric GCM. J Clim 23(13):36763698. doi:10.1175/2010jcli3261.1

Liu WT, Xie X, Niiler PP (2007) Ocean-atmosphere interaction over agulhas extension meanders. J Clim 20(23):5784-5797. doi:10.1 175/2007jcli1732.1

Mapes BE, Warner TT, Xu M (2003) Diurnal patterns of rainfall in northwestern South America. Part III: diurnal gravity waves and nocturnal convection offshore. Mon Wea Rev 131 (5):830-844. doi:10.1175/1520-0493(2003)131<0830:dporin>2.0.co;2

Minobe S, Kuwano-Yoshida A, Komori N, Xie S-P, Small RJ (2008) Influence of the Gulf Stream on the troposphere. Nature 452(7184):U206-U251. doi:10.1038/nature06690

Minobe S, Miyashita M, Kuwano-Yoshida A, Tokinaga H, Xie S-P (2010) Atmospheric response to the Gulf Stream: seasonal variations. J Clim 23(13):3699-3719. doi:10.1175/2010jcli3359.1

Nakamura H, Sampe T, Tanimoto Y, Simpo A (2004) Observed associations among storm tracks, jet streams and midlatitude oceanic 
fronts. In: Wang C, Xie SP, Carton JA (eds) The Earth's climate: the ocean-atmosphere interaction, Geophys. Monogr., vol 147. Amer. Geophys. Union, pp 329-346

Nakamura H, Sampe T, Goto A, Ohfuchi W, Xie S-P (2008) On the importance of midlatitude oceanic frontal zones for the mean state and dominant variability in the tropospheric circulation. Geophys Res Lett 35 (15). doi:10.1029/2008g1034010

Nakamura H, Nishina A, Minobe S (2012) Response of storm tracks to bimodal Kuroshio path states south of Japan. J Clim 25(21):7772-7779. doi:10.1175/jcli-d-12-00326.1

Nesbitt SW, Zipser EJ (2003) The diurnal cycle of rainfall and convective intensity according to three years of TRMM measurements. J Clim 16(10):1456-1475. doi:10.1175/1520-0442-16.10.1456

Ninomiya K, Akiyama T (1992) Multiscale features of Baiu, the summer monsoon over Japan and the East-Asia. J Meteor Soc Jpn 70(1B):467-495

Nonaka M, Nakamura H, Taguchi B, Komori N, Kuwano-Yoshida A, Takaya K (2009) Air-sea heat exchanges characteristic of a prominent midlatitude oceanic front in the South Indian Ocean as simulated in a high-resolution coupled GCM. J Clim 22(24):6515-6535. doi:10.1175/2009jcli2960.1

Ogawa F, Nakamura H, Nishii K, Miyasaka T, Kuwano-Yoshida A (2012) Dependence of the climatological axial latitudes of the tropospheric westerlies and storm tracks on the latitude of an extratropical oceanic front. Geophys Res Lett 39. doi:10.1029/2 $011 \mathrm{~g} 1049922$

Oki T, Musiake K (1994) Seasonal change of the diurnal cycle of precipitation over Japan and Malaysia. J Appl Meteorol 33(12):1445-1463. doi:10.1175/1520-0450(1994)033<1445:scot $\mathrm{dc}>2.0 . \mathrm{co} ; 2$

Randall DA, Harshvardhan, Dazlich DA (1991) Diurnal variability of the hydrologic-cycle in a general-circulation model. J Atmos Sci 48(1):40-62. doi:10.1175/1520-0469(1991)048<0040:dvothc $>2$. $0 . \mathrm{co} ; 2$

Reynolds RW, Smith TM, Liu C, Chelton DB, Casey KS, Schlax MG (2007) Daily high-resolution-blended analyses for sea surface temperature. J Clim 20(22):5473-5496. doi:10.1175/2007j cli1824.1

Rickenbach T, Kucera P, Gentry M, Carey L, Lare A, Lin RF, Demoz B, Starr DO (2008) The relationship between anvil clouds and convective cells: a case study in South Florida during CRYSTALFACE. Mon Wea Rev 136(10):3917-3932. doi:10.1175/2008 mwr2441.1

Rossow WB, Schiffer RA (1999) Advances in understanding clouds from ISCCP. Bull Am Meteor Soc 80(11):2261-2287. doi:10.1175/1520-0477(1999)080<2261:aiucfi>2.0.co;2

Rudeva I, Gulev SK (2011) Composite analysis of North Atlantic extratropical cyclones in NCEP-NCAR reanalysis data. Mon Wea Rev 139(5):1419-1446. doi:10.1175/2010mwr3294.1

Saha S, Moorthi S, Pan HL, Wu XR, Wang JD, Nadiga S, Tripp P, Kistler R, Woollen J, Behringer D, Liu HX, Stokes D, Grumbine R, Gayno G, Wang J, Hou YT, Chuang HY, Juang HMH, Sela J, Iredell M, Treadon R, Kleist D, Van Delst P, Keyser D, Derber J, Ek M, Meng J, Wei HL, Yang RQ, Lord S, Van den Dool H, Kumar A, Wang WQ, Long C, Chelliah M, Xue Y, Huang BY, Schemm JK, Ebisuzaki W, Lin R, Xie PP, Chen MY, Zhou ST, Higgins W, Zou CZ, Liu QH, Chen Y, Han Y, Cucurull L, Reynolds RW, Rutledge G, Goldberg M (2010) The NCEP climate forecast system reanalySIS. Bull Am Meteor Soc 91(8):10151057. doi:10.1175/2010bams3001.1

Sampe T, Xie SP (2007) Mapping high sea winds from space: a global climatology. Bull Am Meteor Soc 88(12):1965. doi:10.1175/b ams-88-12-1965

Sampe T, Xie SP (2010) Large-Scale dynamics of the Meiyu-Baiu rainband: environmental forcing by the westerly jet. J Clim 23(1):113-134. doi:10.1175/2009jcli3128.1
Sasaki YN, Minobe S, Asai T, Inatsu M (2012) Influence of the Kuroshio in the East China Sea on the early summer (Baiu) rain. J Clim 25(19):6627-6645. doi:10.1175/jcli-d-11-00727.1

Shaman J, Samelson RM, Skyllingstad E (2010) Air-sea fluxes over the Gulf Stream region: atmospheric controls and trends. J Clim 23(10):2651-2670. doi:10.1175/2010jcli3269.1

Shimada T, Minobe S (2011) Global analysis of the pressure adjustment mechanism over sea surface temperature fronts using AIRS/ Aqua data. Geophys Res Lett 38. doi:10.1029/2010g1046625

Small RJ, deSzoeke SP, Xie SP, O’Neill L, Seo H, Song Q, Cornillon P, Spall M, Minobe S (2008) Air-sea interaction over ocean fronts and eddies. Dyn Atmos Oceans 45(3-4):274-319. doi:10.1016/j.dynatmoce.2008.01.001

Stackhouse PW, Gupta SK, Cox SJ, Colleen MJ, Zhang T, Chiacchio M (2004) Twelve-year surface radiation budget data set. GEWEX News 14(4):10-12

Sui CH, Lau KM, Takayabu YN, Short DA (1997) Diurnal variations in tropical oceanic cumulus convection during TOGA COARE. J Atmos Sci 54(5):639-655. doi:10.1175/1520-0469(1997) 054<0639:dvitoc >2.0.co;2

Taguchi B, Nakamura H, Nonaka M, Xie S-P (2009) Influences of the Kuroshio/Oyashio Extensions on Air-Sea Heat Exchanges and Storm-Track activity as revealed in regional atmospheric model simulations for the 2003/04 cold season. J Clim 22(24):65366560. doi: $10.1175 / 2009$ jcli2910.1

Tao WK, Lang S, Simpson J, Sui CH, Ferrier B, Chou MD (1996) Mechanisms of cloud-radiation interaction in the tropics and midlatitudes. J Atmos Sci 53(18):2624-2651. doi:10.1175/1520-0469(1996) 053<2624:mocrii >2.0.co;2

Tokinaga H, Tanimoto Y, Xie S-P, Sampe T, Tomita H, Ichikawa H (2009) Ocean frontal effects on the vertical development of clouds over the western North Pacific: in situ and satellite observations. J Clim 22(16):4241-4260. doi:10.1175/2009jcli2763.1

Ushio T, Sasashige K, Kubota T, Shige S, Okamoto K, Aonashi K, Inoue T, Takahashi N, Iguchi T, Kachi M, Oki R, Morimoto T, Kawasaki ZI (2009) A Kalman filter approach to the global satellite mapping of precipitation (GSMaP) from combined passive microwave and infrared radiometric data. J Meteor Soc Jpn 87:137-151. doi:10.2151/jmsj.87A.137

Wallace JM (1975) Diurnal-variations in precipitation and thunderstorm frequency over conterminous united-states. Mon Wea Rev 103(5):406-419. doi:10.1175/1520-0493(1975)103<0406:dvipat $>2.0 . \operatorname{co} ; 2$

Wang B, LinHo (2002) Rainy season of the Asian-Pacific summer monsoon. J Clim 15(4):386-398. doi:10.1175/1520-0442(2002) 015<0386:rsotap >2.0.co;2

Xie SP (2004) Satellite observations of cool ocean-atmosphere interaction. Bull Am Meteor Soc 85(2):195. doi:10.1175/bams85-2-195

Xu HM, Xu MM, Xie SP, Wang YQ (2011) Deep atmospheric response to the spring Kuroshio over the East China Sea. J Clim 24(18):4959-4972. doi:10.1175/jcli-d-10-05034.1

Yang GY, Slingo J (2001) The diurnal cycle in the tropics. Mon Wea Rev 129(4):784-801. doi:10.1175/1520-0493(2001)129<0784: tdcitt>2.0.co;2

Yang S, Smith EA (2006) Mechanisms for diurnal variability of global tropical rainfall observed from TRMM. J Clim 19(20):5190 5226. doi:10.1175/JCLI3883.1

Zolina O, Gulev SK (2003) Synoptic variability of ocean-atmosphere turbulent fluxes associated with atmospheric cyclones. J Clim 16(16):2717-2734. doi:10.1175/1520-0442(2003)016<2717:svo otf $>2.0 . \operatorname{co} ; 2$

Zuidema P (2003) Convective clouds over the Bay of Bengal. Mon Wea Rev 131(5):780-798. doi:10.1175/1520-0493(2003)131<0780: ccotbo $>2.0 . c 0 ; 2$ 